\title{
Roles of the 14-3-3 gene family in cotton flowering
}

Na Sang ${ }^{1,2+}$, Hui Liư ${ }^{2 \dagger}$, Bin Ma², Xianzhong Huang ${ }^{2,3^{*}}$, Lu Zhuo $^{2}$ and Yuqiang Sun ${ }^{4}$

\begin{abstract}
Background: In plants, 14-3-3 proteins, also called GENERAL REGULATORY FACTORs (GRFs), encoded by a large multigene family, are involved in protein-protein interactions and play crucial roles in various physiological processes. No genome-wide analysis of the GRF gene family has been performed in cotton, and their functions in flowering are largely unknown.

Results: In this study, 17, 17, 31, and 17 GRF genes were identified in Gossypium herbaceum, G. arboreum, G. hirsutum, and G. raimondii, respectively, by genome-wide analyses and were designated as GheGRFs, GaGRFs, GhGRFs, and GrGRFs, respectively. A phylogenetic analysis revealed that these proteins were divided into $\varepsilon$ and non$\varepsilon$ groups. Gene structural, motif composition, synteny, and duplicated gene analyses of the identified GRF genes provided insights into the evolution of this family in cotton. GhGRF genes exhibited diverse expression patterns in different tissues. Yeast two-hybrid and bimolecular fluorescence complementation assays showed that the GhGRFs interacted with the cotton FLOWERING LOCUS T homologue GhFT in the cytoplasm and nucleus, while they interacted with the basic leucine zipper transcription factor GhFD only in the nucleus. Virus-induced gene silencing in G. hirsutum and transgenic studies in Arabidopsis demonstrated that GhGRF3/6/9/15 repressed flowering and that GhGRF14 promoted flowering.

Conclusions: Here, 82 GRF genes were identified in cotton, and their gene and protein features, classification, evolution, and expression patterns were comprehensively and systematically investigated. The GhGRF3/6/9/15 interacted with GhFT and GhFD to form florigen activation complexs that inhibited flowering. However, GhGRF14 interacted with GhFT and GhFD to form florigen activation complex that promoted flowering. The results provide a foundation for further studies on the regulatory mechanisms of flowering.
\end{abstract}

Keywords: 14-3-3, GENERAL REGULATORY FACTOR, Florigen activation complex, Flowering, Cotton

\section{Background}

The 14-3-3 proteins are highly conserved in virtually every eukaryotic organisms and tissue [1]. Among plants, 14-3-3 genes have been studied most thoroughly in Arabidopsis thaliana, in which the 14-3-3 genes are designated either as G-box Factor 14-3-3 homologs (GF14s)

\footnotetext{
*Correspondence: Huangxz@ahstu.edu.cn

${ }^{\dagger} \mathrm{Na}$ Sang and Hui Liu contributed equally to this work.

${ }^{2}$ Special Plant Genomics Laboratory, College of Life Sciences, Shihezi University, Shihezi 832000, China

${ }^{3}$ Center for Crop Biotechnology, College of Agriculture, Anhui Science and Technology University, Fengyang 233100, China

Full list of author information is available at the end of the article
}

or General regulatory factors (GRFs) [2-4]. The 14-3-3 proteins exist in diversified isoforms that can form homo- and heterodimers, with each monomer consisting of nine $\alpha$-helices in an anti-parallel arrangement and they associate through the N-terminal regions to assemble the dimeric protein. Each 14-3-3 dimer is able to interact with two different target proteins at the same time [5-7].

The 14-3-3 proteins in plants function in ubiquitous physiological processes, such as growth and development, cell metabolism, signal transduction, stress responses, postharvest ripening, and nitrogen fixation. In

(c) The Author(s). 2021 Open Access This article is licensed under a Creative Commons Attribution 4.0 International License, which permits use, sharing, adaptation, distribution and reproduction in any medium or format, as long as you give appropriate credit to the original author(s) and the source, provide a link to the Creative Commons licence, and indicate if changes were made. The images or other third party material in this article are included in the article's Creative Commons licence, unless indicated otherwise in a credit line to the material. If material is not included in the article's Creative Commons licence and your intended use is not permitted by statutory regulation or exceeds the permitted use, you will need to obtain permission directly from the copyright holder. To view a copy of this licence, visit http://creativecommons.org/licenses/by/4.0/ The Creative Commons Public Domain Dedication waiver (http://creativecommons.org/publicdomain/zero/1.0/) applies to the data made available in this article, unless otherwise stated in a credit line to the data. 
Arabidopsis, the T-DNA insertion mutants $14-3-3 \mu$ and 14-3-3 result in a delay of flowering under long-day (LD) conditions [8]. The 14-3-3 proteins SGF14c and SGF14l from Glycine max play important roles in early developmental stages of soybean nodules [9]. In banana (Musa acuminata), MaGRFs have significant transcriptional responses during fruit development and postharvest ripening [10]. The 14-3-3 proteins also function in abiotic stress responses [11]. The overexpression of

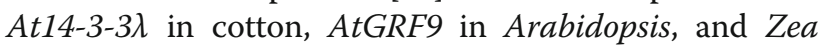
mays GF14-6 in rice (Oryza sativa) enhance drought resistance [12-14]. Five OsGRFs (OsGF14b/c/d/e/f) and three Vitis vinifera GRFs (VviGRF15/17/like2) show significant expression changes under cold stress in rice and grape, respectively $[15,16]$.

In recent years, an increasing number of studies on the interactions between 14-3-3 proteins and other proteins have been performed. For example, tomato (Solanum lycopersicum) 14-3-3/74 protein interacts with the SELF-PRUNING protein, which is homologous to CENTRORADIALIS in Antirrhinum and TERMINAL FLOWER1 in Arabidopsis. Furthermore, the overexpression of the 14-3-3/2 and 14-3-3/74 genes complements the loss of function of SELF-PRUNING [17, 18]. The overexpression of GF14c from Phyllostachys violascens in Arabidopsis significantly delays flowering time under LD conditions, and PvGF14c interacts with the FLOWERING LOCUS T (FT) homologues PvFT and AtFT in the cytoplasm [19]. The rice FT homologue Hd3a interacts with 14-3-3 proteins to form a complex and binds to the basic leucine zipper transcription factor OsFD1 to form a florigen activation complex (FAC) and induce the transcription of OsMADS15, a homologue of A. thaliana APETALA1 (AP1), leading to flowering [8]. This FACrelated phenomenon also exists in Arabidopsis [20]. Furthermore, the serine/threonine residue in the C-terminal phosphorylation motif of FD and the arginine residue in the phosphoserine-binding pocket of the 14-3-3 protein are required for the interaction between 14-3-3 and FD proteins [21, 22].

Upland cotton (Gossypium hirsutum), an important economic crop, is a major cultivated fiber crop worldwide [23]. The cloning and characterization of the 14-33 genes in G. hirsutum have attracted attention. The cotton 14-3-3 genes appear to function in fiber cell initiation and elongation, salt and drought stress signaling, and Verticillium dahlia resistance [24-28]. At present, the 14-3-3 genes of several plants have been identified, such as Arabidopsis [29-31], rice [15, 32], Medicago truncatula [33], Phyllostachys violascens [19], soybean [34], and foxtail millet (Setaria italica) [35]. However, systematic investigations of 14-3-3 family members using genome sequences and of their functions in flowering have not been reported for G. hirsutum.
In this study, 82 GRF genes were identified from the genome data of G. herbaceum, G. arboreum, G. hirsutum, and G. raimondii by genome-wide identification. We analyzed their chromosomal distributions, phylogenic relationships, gene structures, motifs, synteny, duplicated genes, and promoter cis-acting elements in detail. The expression profiles of GhGRF genes in various organs of ovules and fibers at different developmental stages were comprehensively characterized, and biochemical experiments verified that GhGRF proteins interacted with the cotton FT homologue GhFT and bZIP transcription factor FD homologue GhFD to form a FAC. In addition, our transgenic research showed that GhGRF3, GhGRF6, GhGRF9, GhGRF14, and GhGRF15 were involved in flowering. The present results provide a foundation for the further functional characterization of the GRF gene family and the genetic improvement of cotton.

\section{Results \\ Identification and chromosomal distributions of the GRF family genes in cotton}

A total of 24, 24, 45, and 61 GRF protein sequences were identified from genome databases of four cotton species, G. herbaceum, G. arboreum, G. hirsutum, and G. raimondii, respectively, using Hidden Markov Model (HMM) searches. Conserved domain database and Pfam were used to further confirm the presence of the 14-3-3 domain. After removing partial and redundant sequences, 17, 17, 31, and 17 potential GRF genes were identified by genome-wide identification from $G$. herbaceum, G. arboreum, G. hirsutum, and G. raimondii, respectively. In total, $31 \mathrm{G}$. hirsutum GRF proteins were named based on their phylogenetic relationships and amino acid sequence similarities with Arabidopsis GRFs. If the amino acid sequences from the $\mathrm{A}$ or $\mathrm{D}$ subgenome had one-to-one similarities with Arabidopsis GRF members, they were named the corresponding Arabidopsis name, such as AtGRF1 and GhGRF1-A/D. Because there are only 13 GRFs in Arabidopsis, the remaining members containing the same 14-3-3 domain were named GhGRF14-17-A/D (Additional file 1: Table S1). GRF proteins recognized from the diploid cotton genomes were named on the basis of the corresponding name in G. hirsutum (Additional file 2: Table S2). The GRF proteins identified in cotton ranged from 148 to 421 amino acids. Their molecular weights ranged from 17 to $105 \mathrm{kDa}$, and the isoelectric points from 4.48 to 6.55 (Additional file 3: Table S3).

Cotton GRF genes were not distributed on all 13 chromosomes. In G. herbaceum, 17 GheGRF genes were located on seven different chromosomes, with chromosome 05 having five genes (GheGRF1, 8, 10, 11, and 13), while chromosomes 01 (GheGRF2 and 16), 03 (GheGRF4 
and 6), 06 (GheGRF9 and 12), 07 (GheGRF7 and 18), and 13 (GheGRF14 and 17) contained two genes each. GheGRF15 was located on chromosome 04 (Additional file 4: Fig. S1a). In G. arboreum, chromosome 10 contained three genes (GaGRF5, 8 and 10), while chromosomes 01 (GaGRF7 and 13), 04 (GaGRF1-1 and 11), 08 (GaGRF9 and 14), 12 (GaGRF1-2 and 15), and 13 (GaGRF12 and 17) contained two genes each. The genes GaGRF6, 4, and 2 were located on chromosomes 03, 05, and 07, respectively (Additional file 4: Fig. S1b). In G. hirsutum, chromosomes A02, D02, A03, A04, D04, D06, and A07 contained one gene each, GhGRF6-A, GhGRF6$D$, GhGRF4-A, GhGRF15-A, GhGRF15-D, GhGRF9-D, and GhGRF7-A, respectively. Two genes were found on chromosomes A01 (GhGRF2-A and 16-A), D01 (GhGRF2-D and 16-D), A06 (GhGRF9-A and 14-A), A13 (GhGRF12-A and 17-A) and D13 (GhGRF12-D and 17$D)$. In addition, three genes (GhGRF3-D, 5-D, and 7-D) were located on chromosome D07, and five genes were on both chromosomes A05 (GhGRF1-A, 8-A, 10-A, 11$A$, and 13-A) and D05 (GhGRF1-D, 8-D, 10-D, 11-D, and 13-D) (Additional file 4: Fig. S1c). Similarly, chromosome 09 had the largest number of GRF genes (GrGRF1, $8,10,11$, and 13), followed by chromosome 01 with three genes (GrGRF3, 5, and 7). Chromosomes 02 (GrGRF2 and 16), 05 (GrGRF6 and 19), and 13 (GrGRF12 and 17) contained two genes each, and the last three genes (GrGRF18, 9, and 15) were located on the chromosomes 06, 10, and 12, respectively (Additional file 4: Fig. S1d).

\section{Multiple sequences alignment and phylogenetic analysis of GRF family members in cotton}

The multiple amino acid sequence alignment revealed nine $\alpha$-helices in cotton GRF protein secondary structures, of which $\alpha 3$ and $\alpha 4$ were the longest (Additional file 5: Fig. S2). To examine the evolutionary relationships among GRF gene family members in cotton, we constructed a phylogenetic tree with the neighbor-joining [36] method using 17 G. herbaceum, 17 G. arboreum, $31 \mathrm{G}$. hirsutum, $17 \mathrm{G}$. raimondii, 13 Arabidopsis, 8 rice, 14 Populus trichocarpa, 7 Brachypodium distachyon, and 8 foxtail millet members' GRF amino acid sequences (Fig. 1). The 132 GRF proteins were classified into two major groups: $\varepsilon$ and non- $\varepsilon$. According to the phylogenetic relationship, four GRF proteins of G. herbaceum (GheGRF9, 10, 11, and 14), G. arboreum (GaGRF9, 10, 11, and 12) and G. raimondii (GrGRF9, 10, 11, and 12), along with eight GRF proteins from G. hirsutum (GhGRF9-A, 10-A, 11-A, 12-A, 9-D, 10-D, 11-D, and 12-D), five from Arabidopsis (AtGF9, $10,11,12$, and 13), two from rice (OsGF14g and h), seven from $P$. trichocarpa (PtGRF9a, 9b, 11a, 11b, 12a, $12 \mathrm{~b}$, and 13), one form $B$. distachyon (BdGF14g), and one from foxtail millet (SiGRF8) were encoded by genes belonging to the $\varepsilon$ group. The other 96 GRF genes belonged to the non- $\varepsilon$ group.

\section{Analyses of cotton GRF gene structures and GRF protein motifs}

Gene structural divergence plays a main role in the evolution of gene families. To characterize the gene structures of the GRF genes identified from four Gossypium species, a phylogenetic tree was constructed (Fig. 2a), and the exon-intron structures of 82 GRF genes were analyzed. The GRF genes contained two to seven exons, with 20 genes in the non- $\varepsilon$ group possessing five to seven exons, while the $\varepsilon$ group members possessed two to five exons (Fig. 2b). The diversity of the exon-intron structures between the $\varepsilon$ and non- $\varepsilon$ groups in cotton indicated differences in the expansion and evolution of the $\varepsilon$ and non- $\varepsilon$ groups of cotton GRF genes. In the $\varepsilon$ group, genes composed of five exons were from the allotetraploid G. hirsutum, such as GhGRF1-A and GhGRF13-D, suggesting that some $\varepsilon$ group members obtained additional exons during the polyploidization process.

Seven conserved motifs were identified from cotton GRF proteins using an online MEME program [37] and further annotated by InterPro [38]. The lengths of motifs ranged from 21 to 50 amino acids, and motifs $1,2,3$, and 4 were annotated as 14-3-3 protein domains (Additional file 6: Table S4). Motifs 3 and 6 existed in all of the GRF proteins of cotton, showing high conservation, indicating that they may be requisite for gene function. In the $\varepsilon$ group, most GRF proteins contained motifs 4 and 7 at the $\mathrm{N}$ and $\mathrm{C}$ termini, respectively. Most of the non- $\varepsilon$ group had either motif 4 or 7 at the $\mathrm{N}$ terminus, and they all had motif 1 at the $C$ terminus (Fig. 2c). The differences in motif structures between $\varepsilon$ and non- $\varepsilon$ groups may reflect their functional diversity.

\section{Synteny and duplicated gene analysis of cotton GRF genes}

To deduce the phylogenetic mechanisms of the GRF family in G. hirsutum, we constructed comparative syntenic maps of G. hirsutum with the other three Gossypium species, including the A subgenome of G. hirsutum with the diploid A-genome cotton species $G$. herbaceum and G. arboreum, and the D subgenome of G. hirsutum with the A subgenome and diploid Dgenome G. raimondii (Fig. 3). A total of 20 and 15 GRF genes from $\mathrm{A}_{\mathrm{t}}$-subgenome of $\mathrm{G}$. hirsutum exhibited syntenic relationships with those in G. herbaceum and G. arboreum, respectively, while 19 and $17 G R F$ genes from the $D_{t}$-subgenome of $G$. hirsutum showed syntenic relationships with those in the A subgenome and G. raimondii, respectively (Fig. 3 and Additional file 7: Table S5). Some GRF genes formed two or three syntenic gene 


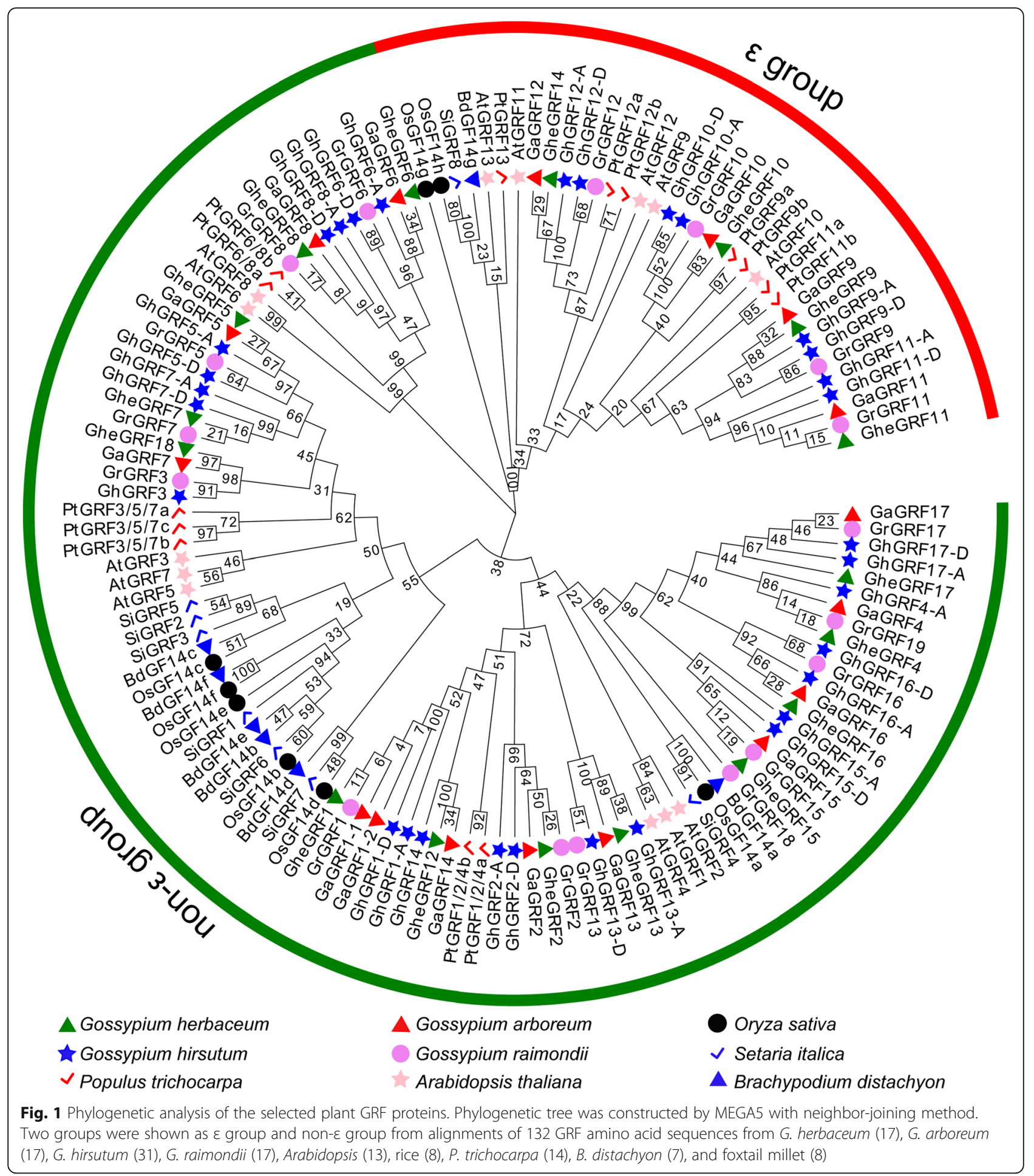

pairs (particularly between the $A_{t}$-subgenome of G. hirsutum and the D subgenome of G. hirsutum, and the $\mathrm{A}_{\mathrm{t}^{-}}$ subgenome of $G$. hirsutum and G. herbaceum), such as GhGRF4-A and GhGRF15-A from the $\mathrm{A}_{\mathrm{t}}$-subgenome of G. hirsutum. We hypothesize that these genes played crucial roles in the evolution of the GRF gene family.
Gene duplication is generally considered to be a necessary source of material for the generation of evolutionary novelties and the production of new gene functions [39, 40]. A genome duplication analysis revealed that 12,12 , 49 , and 15 paralogous pairs were duplicated GRF gene pairs (Additional file 8: Table S6). To better understand 


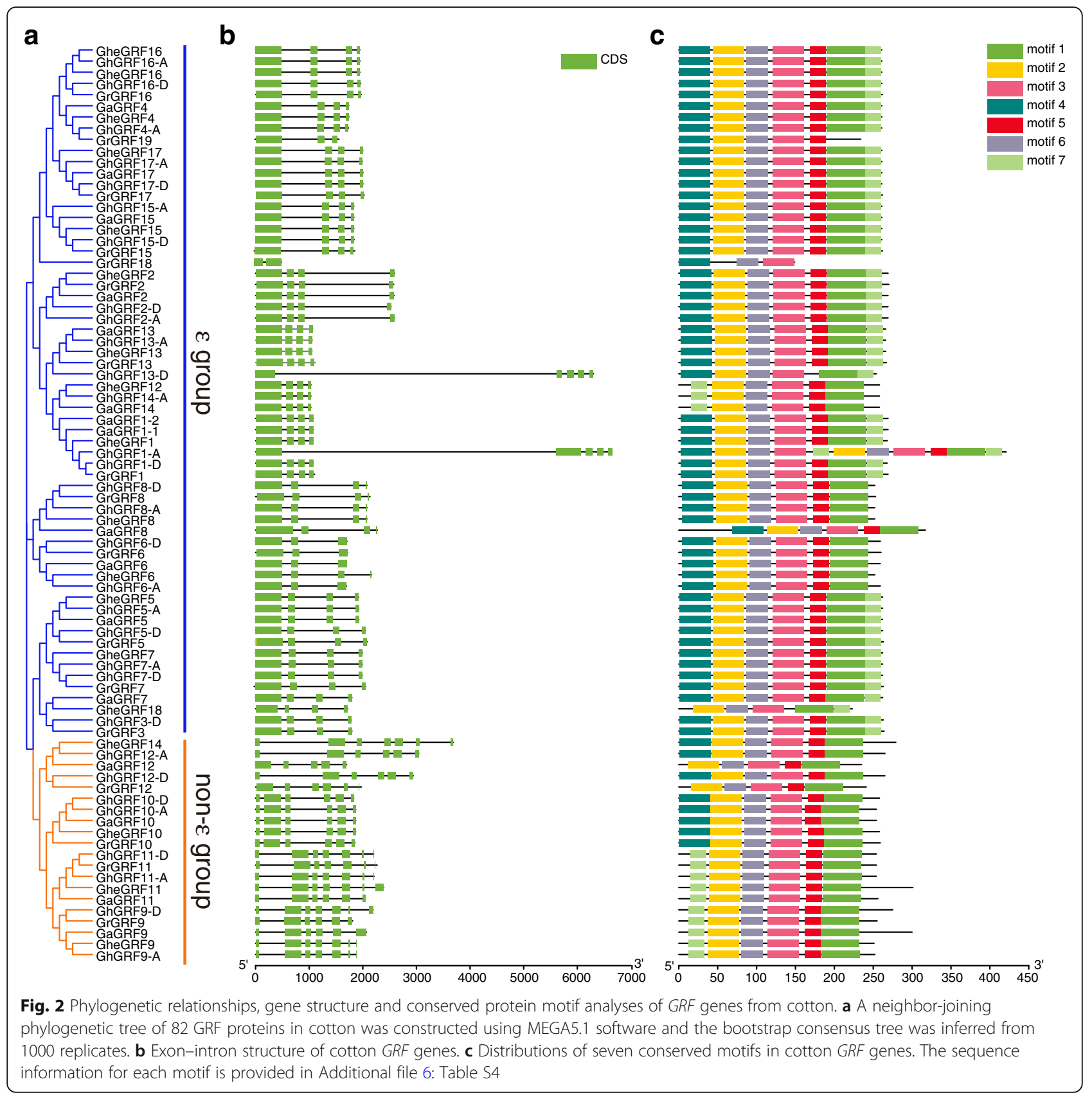

the selective evolutionary pressure on this gene family, the non-synonymous $(K a)$ and synonymous $(K s)$ substitution ratios of these gene pairs were calculated (Additional file 7: Table S5 and Additional file 8: Table S6). The paralogous pairs in all four cotton species had $K a / K s<1$, suggesting that the cotton GRF gene family has undergone strong purifying selection during evolution (Additional file 9: Fig. S3a). The syntenic gene pairs, except for the pair GhGRF9$D$ and GrGRF9, which were from D subgenome of G. hirsutum and G. herbaceum, respectively, experienced positive selection $(K a / K s>1)$, having evolved under purifying selection $(K a / K s<1)$ (Additional file 9: Fig. S3b).
Prediction of cis-acting elements in cotton GRF promoters To determine whether the regulatory mechanism was influenced by cis-acting elements in GRF promoters, the sequences $2.0-\mathrm{kb}$ upstream of the translation start sites were analyzed. A number of putative cis-elements in the four Gossypium species may be involved in various responses, such as to light, anaerobic induction, methyl jasmonate (MeJA), abscisic acid, salicylic acid, and auxin. Among these elements, light responsive element was the most abundant responses, followed by anaerobic induction and MeJA-responsive (Additional file 10: Fig. S4). 


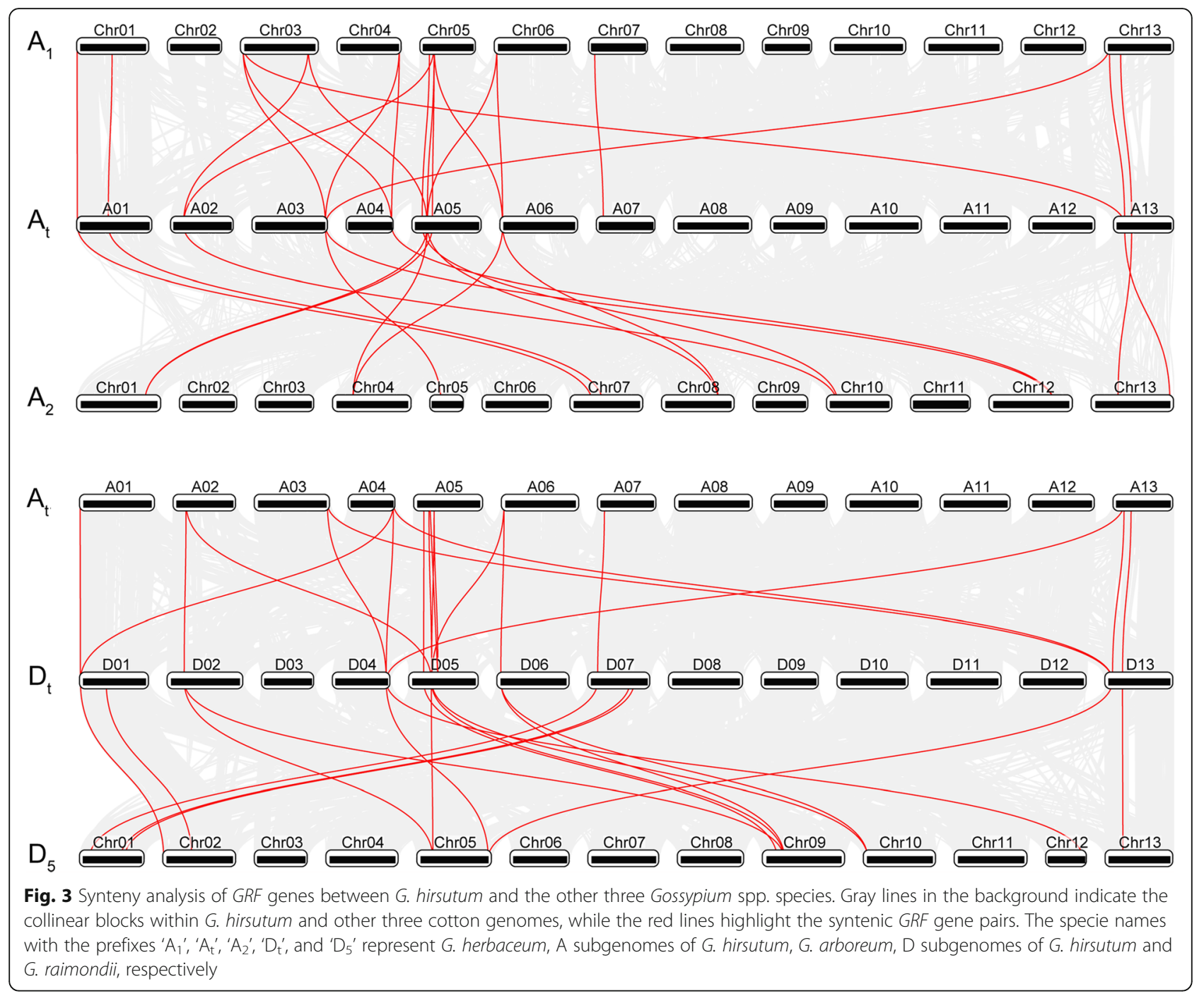

A total of 25 cis-acting elements related to light responsiveness were recognized, including an AE-box, GTGGC-motif, GT1-motif, Box 4, TCT-motif, G-Box, Sp1, MRE, and I-box. Some gibberellin-responsive elements were found, including a TATC-box, P-box, and GARE-motif. Two MeJA-responsive elements (CGTCAmotif and TGACG-motif), auxin-responsive elements (AuxRR-core and TGA-element), endosperm expression elements (GCN4-motif and AAAC-motif), and salicylic acid-responsive elements (TCA-element and SARE) were identified. Anaerobic induction elements, such as AREs were observed. In addition, other abiotic stressresponse factors, such as an MBS, circadian, LTR, WUN-motif, ARE, and TC-rich repeats, were also present (Additional file 11: Fig. S5).

\section{Expression profiles of GRF genes in G. hirsutum}

To analyze the expression patterns of the identified GRF genes in cotton, 15 tissues, including roots, stems, leaves, sepals, petals, pistils, filaments, ovules, and fibers, at different developmental stages were selected and their expression levels analyzed using published RNA-seq data (PRJNA490626) [41]. In total, 31 GhGRFs exhibited differential expression levels in the investigated tissues (Fig. 4a). The values of fragments per kilobase of exon model per million mapped reads (FPKM) for four GhGRF genes (GhGRF12-A, GhGRF12-D, GhGRF13-D, and GhGRF14-A) were equal to 0 in some tissues and two genes (GhGRF2-A and GhGRF13-A) had $0<$ FPKM $<1$. The FPKM values of 25 GhGRFs detected in all 15 samples were greater than 1 (Additional file 12: Table S7). Fifteen GhGRF genes were highly expressed in all the tested tissues, including GhGRF5-A, GhGRF8-D, GhGRF11-A, GhGRF11-D, GhGRF15-A, and GhGRF15$D$, which suggested that they are involved in the whole process of cotton growth and development. Nine GhGRF genes were also expressed in all the tissues at relative lower expression levels compared with the 15 highly 


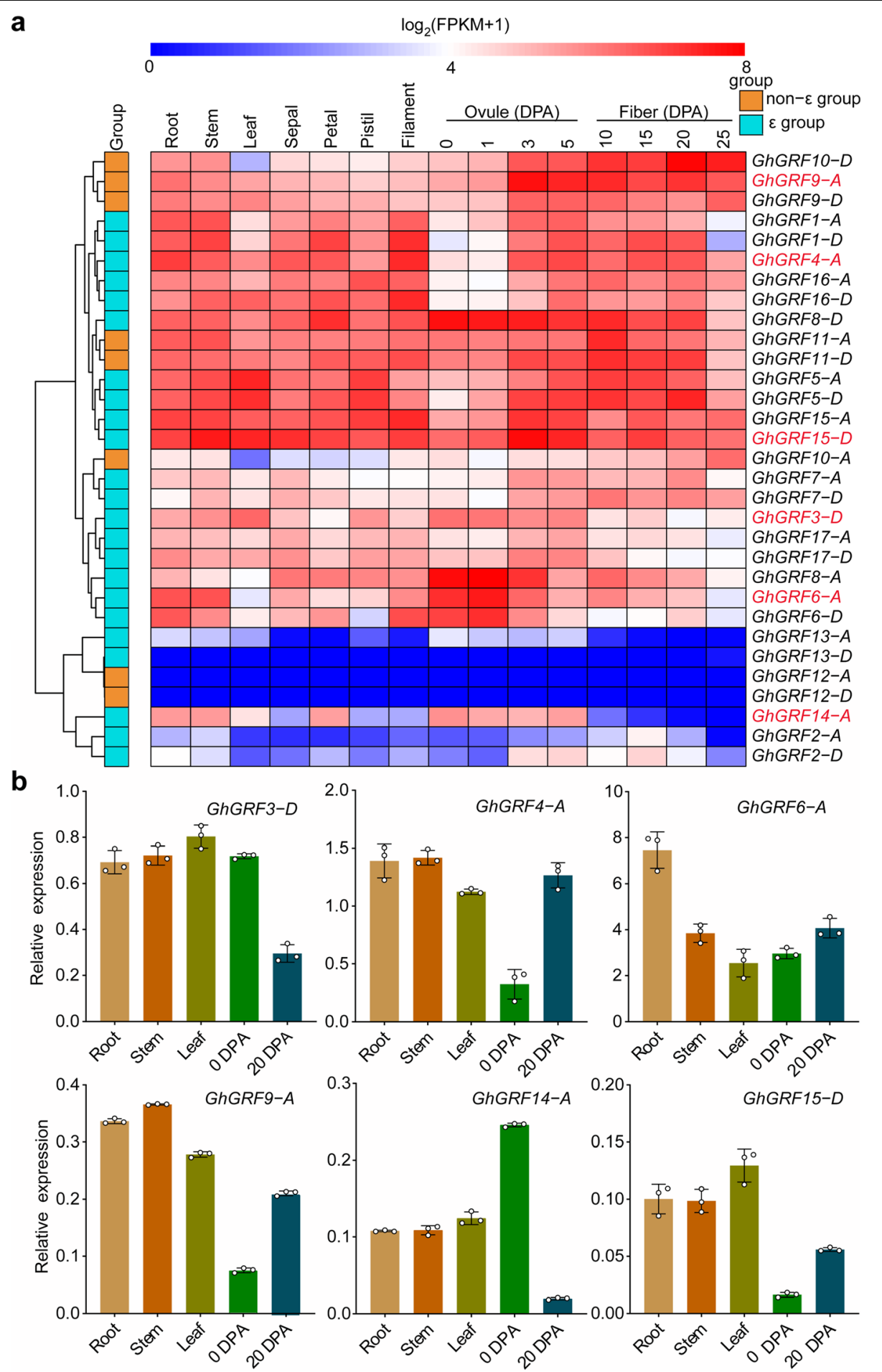

Fig. 4 Expression profiles of GhGRF genes in 15 tissues. a Roots, stems, leaves, sepals, petals, pistils, filaments, fiber-bearing ovules on 0, 1, 3, and 5 d post-anthesis (DPA), and fibers on 10, 15, 20, and 25 DPA were sampled. $\mathbf{b}$ Expression analysis of six GhGRF genes marked with red fonts in $\mathbf{a}$ by qRT-PCR in five samples

expressed genes. However, the expression levels of GhGRF8- $A$ and GhGRF6-A, and GhGRF6-D were similar to those of the 15 genes in ovules at 0 and $1 \mathrm{~d}$ postanthesis (DPA). Seven GhGRF genes showed lower expression levels than these genes, but GhGRF14-A was highly expressed in roots, stems, petals, and ovules. Thus, they might play important roles as tissue-specific regulators. 
Subsequently, quantitative real-time PCR (qRT-PCR) experiments were performed for six representative GhGRF genes to further verify the reliability of the transcriptome data. Roots, stems, leaves, ovules at 0 DPA, and fibers at 20 DPA were used as samples (Fig. 4b). GhGRF3-D and GhGRF14-A were highly expressed in roots, stems, leaves, and 0-DPA ovules, while GhGRF4$A$, GhGRF9-A, and GhGRF15-D were highly expressed in roots, stems, leaves, and 20-DPA ovules. GhGRF6-A showed the lowest expression level in leaves. The qRTPCR results were mostly consistent with the transcriptome data, and the ubiquitous expression profiles suggested that GRF genes are involved in diverse developmental controls in cotton.

\section{Interactions of GhFT and GhFD with each GhGRF protein} The formation of a FAC containing Hd3a, FD, and 14-33 is critical in mediating flowering [7, 20, 22]. A phylogenetic tree analysis showed that 31 GhGRF homologues clearly divided into five branches (Fig. 5a). To determine whether these GhGRFs form FACs in upland cotton, we selected a representative GhGRF protein from each of the five different branches and performed yeast twohybrid $(\mathrm{Y} 2 \mathrm{H})$ experiments. GhFT and GhFD in upland cotton interacted with the selected GhGRF proteins, GhGRF3-D, GhGRF6-A, GhGRF9-A, GhGRF14-A, and GhGRF15-D, in vitro (Fig. 5b and c). Subsequently, we further verified their interactions using bimolecular fluorescence complementation (BiFC) experiments in the epidermal leaves of Nicotiana benthamiana (Fig. $5 \mathrm{~d}$ and e). Moreover, the GhFT-GhGRF interaction was detected in the cytoplasm and nucleus, and the fluorescence signal of GhFD-GhGRF proteins was localized in the nucleus. Because GhGRF interacted with GhFT and GhFD, we, therefore, inferred that these five GhGRF proteins interact with GhFT and GhFD to form five different FACs. In addition, other GhGRF proteins also interacted with GhFT as assessed by $\mathrm{Y} 2 \mathrm{H}$ experiments (Additional file 13: Fig. S6), suggesting that GhGRFs form FACs with GhFT and GhFD.

\section{The effects of silencing five GhGRF genes on flowering time in G. hirsutum}

To explore the possible roles of GhGRF genes in cotton, we performed a virus-induced gene silencing (VIGS) assay. The flowering times in GhGRF3, -6, - 9, and 15-silenced plants were earlier than that of control plants (Fig. 6a-d and Additional file 14: Fig. S7a-d). However, the flowering time in GhGRF14-silenced plants was much later than that of control plants (Fig. 6e and Additional file 14: Fig. S7e). Gene transcription analyses using qRT-PCR revealed that the expression level of each GhGRF significantly decreased in the corresponding silenced plants (Fig. 6f-j). Moreover, the expression levels of floral meristem-identity genes, $A P 1$ homologues GhAP1 (Gh_D13G0878) and SUPPRESSOR OF OVEREXPRESSION OF CONSTANS 1 (SOC1) homologues GhSOC1 (Gh_A11G0755) in cotton, were upregulated in GhGRF3, -6, - 9, and - 15-silenced plants, whereas they were downregulated in the GhGRF14-silenced plants (Additional file 14: Fig. S7f-o).

\section{The effects of the ectopic expression of five GhGRF genes} on flowering time in transgenic Arabidopsis

To further demonstrate the functions of the five GhGRF genes, we constructed overexpression vectors driven by the Cauliflower mosaic virus $35 \mathrm{~S}$ promoter and generated corresponding transgenic Arabidopsis plants. The transgenic plants overexpressing GhGRF3, -6, - 9, and - 15 experienced delayed flowering compared with wildtype (Col-0) under LD conditions (Fig. 7a). The numbers of rosette leaves and flowering times in GhGRF3, - 6, 9 , and - 15 transgenic plants were greater than those of wild-type (Fig. 7b and c). However, GhGRF14-overexpressing plants exhibited early flowering compared with wild-type (Col-0) (Fig. 7d), and the numbers of rosette leaves and flowering time were less than in wild-type (Fig. 6e and f). To investigate whether the flowering time was related to the expression levels of GhGRF genes in transgenic Arabidopsis, the transcript levels of GhGRF genes were detected in the homologous transgenic lines by qRT-PCR. The expression levels of the GhGRF genes were significantly increased in the transgenic plants (Additional file 15: Fig. S8a and b). The flower meristem-identity genes, AtAP1 and AtSOC1, were downregulated in 35S:GhGRF3, 35S:GhGRF6, 35S: GhGRF9, and 35S:GhGRF15 transgenic plants, while they were upregulated in GhGRF14 overexpressing plants (Additional file 15: Fig. S8c-f), which correlated with their flowering times. These results were consistent with the effect of silencing the five GhGRF genes in the regulation of flowering, suggesting that they have roles in flowering regulation.

\section{Discussion}

The 14-3-3 proteins are highly conserved in eukaryotes [1], and can form homo- and heterodimers [42], which are able to interact with two different target proteins at the same time to form complexes [5-7]. Therefore, they have great effects on many plant biological progresses. In recent years, 14-3-3 families have been identified and studied in many plant species $[16,34,35]$. To date, although research on 14-3-3 family members in G. hirsutum has been performed, it mainly focused on the roles of 14-3-3 in fiber development and stress responses [2428]. However, comprehensive systematic analyses and investigations into their functions in flowering are still limited. 

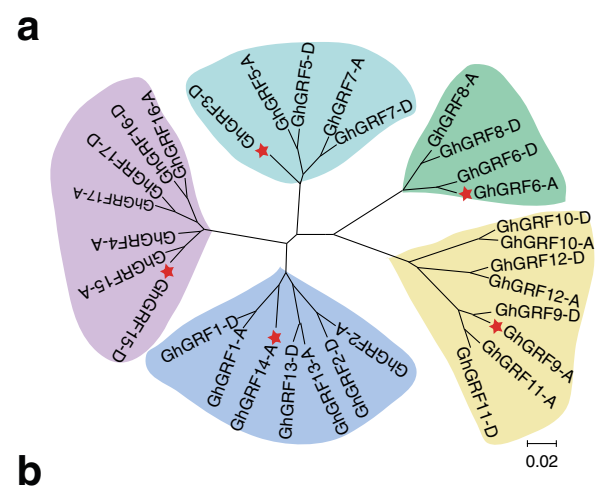

b

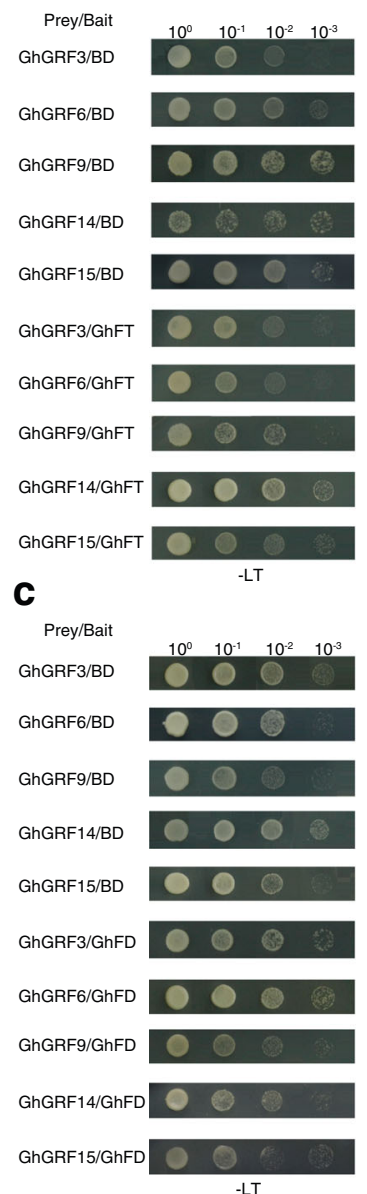

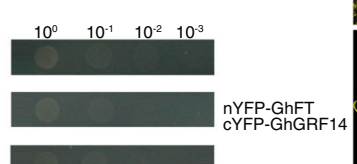

d
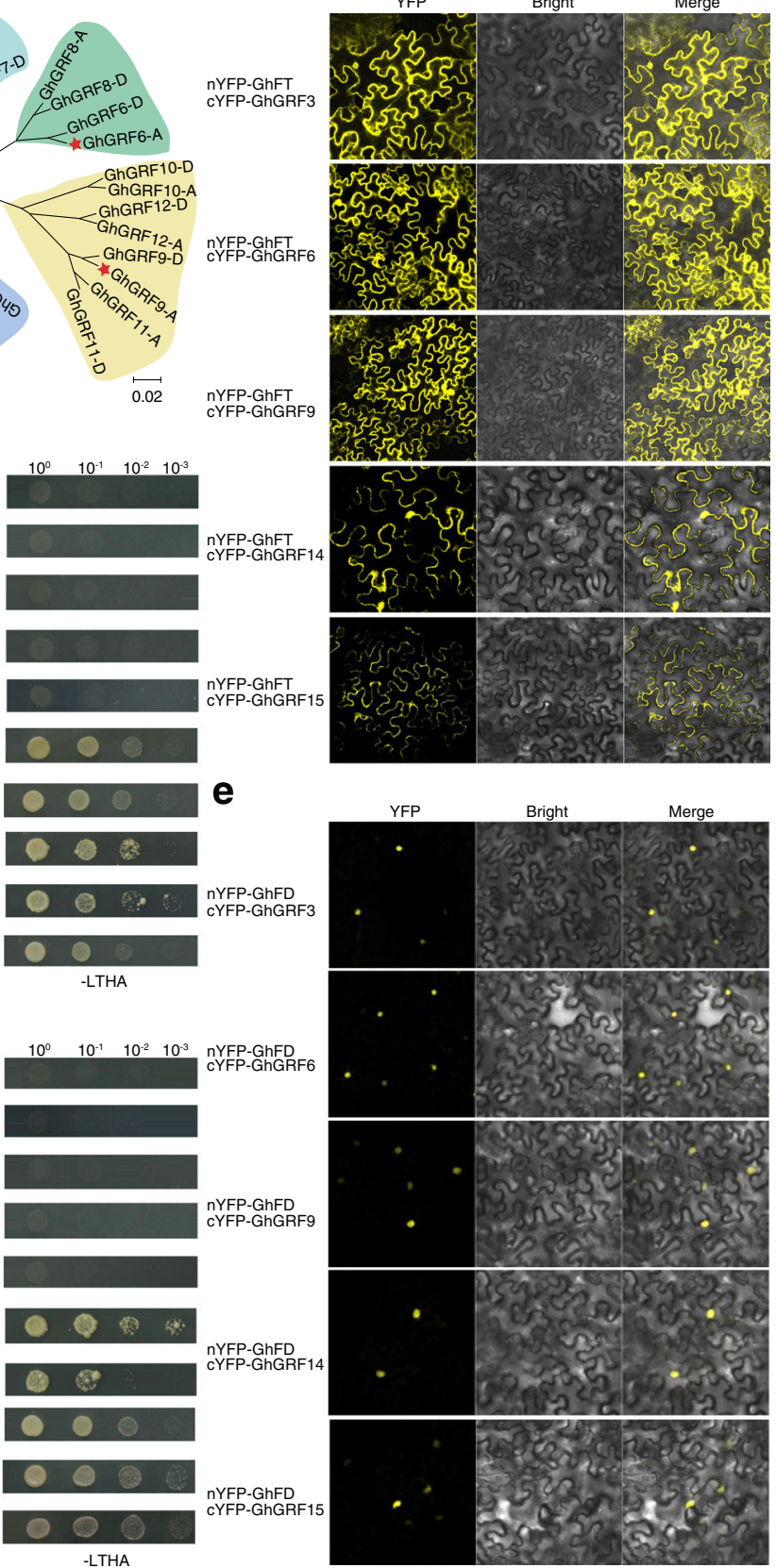

Fig. 5 Interactions of GhFT and GhFD with each GhGRF protein. a Phylogenetic analysis of 31 GhGRF proteins. Red pentagram represent the selected GhGRF proteins used to validate interaction with GhFT. b Y2H experiment between GhFT and each GhGRF protein. c Y2H experiment between GhFD and each GhGRF protein. Plasmids transformed into AH109 yeast strains were screened on the -LT and -LTHA medium. -LT and -LTHA medium represent SD/-Trp-Leu and SD/-Trp-Leu-His-Ade medium. d BiFC verification of interactions between GhFT and each GhGRF protein. e BiFC verification of interactions between GhFD and each GhGRF protein. Constructs of cYFP-GhGRFs and nYFP-GhFD were cotransformed into $N$. benthamiana leaf epidermal cells

The conserved and diverse functions of the GRF gene family in cotton

In this study, genome-wide analyses identified $17,17,31$, and 17 GRF genes from G. herbaceum, G. arboreum, G. hirsutum, and G. raimondii, respectively, in the CottonGen database. The discovery implied that GRF genes had experienced expansion in tetraploid G. hirsutum compared with that in diploid G. herbaceum, G. arboreum, and G. raimondii. On the basis of phylogenetic relationships with other plants, the GRF proteins were classified into $\varepsilon$ and non- $\varepsilon$ group (Fig. 1), which was consistent with previous studies in rice [32], Arabidopsis 

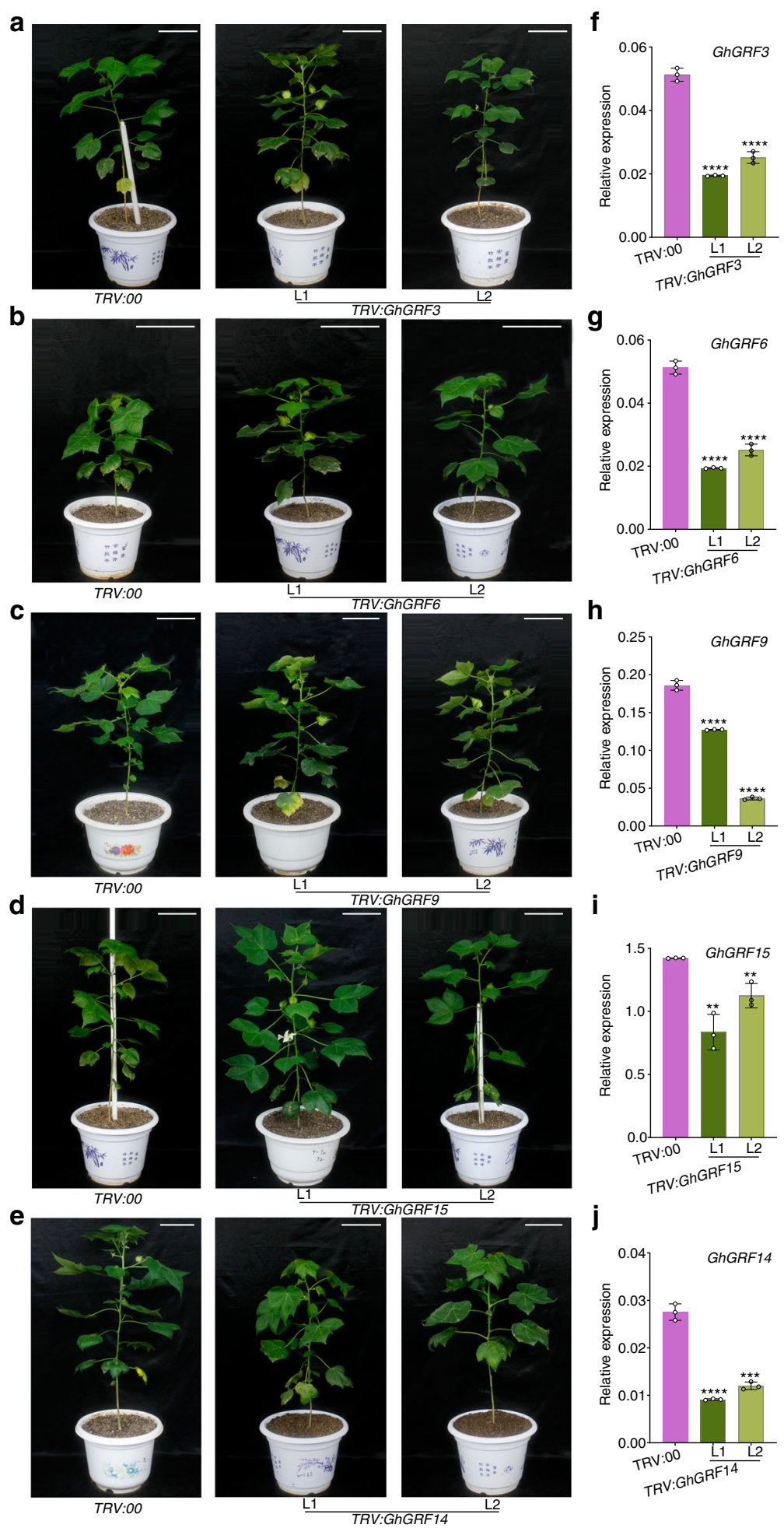

\section{i}

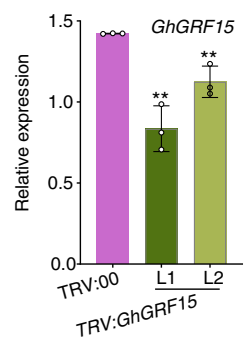

j

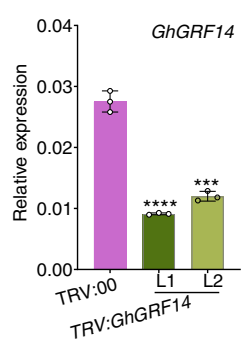

Fig. 6 Phenotypical analyses of silencing of five GhGRF genes in G. hirsutum. Phenotypes of TRV:00 and TRV:GhGRF3 (a), TRV:GhGRF6 (b), TRV:GhGRF9 (c), TRV:GhGRF15 (d), and TRV:GhGRF14 (e). Relative expression of GhGRF3 (f), GhGRF6 (g), GhGRF9 (h), GhGRF15 (i), and GhGRF14 (j) in TRV:00 and TRV:GhGRFs plants. Ubiquitin7 (GhUBQ7, GenBank accession no. DQ116441) gene was used as an internal reference transcript. Values are means $\pm S D(n=3)$. Asterisks indicate significant differences between control TRV:00 and TRV:GhGRFs silencing lines (Student's $t$ test, **P $<0.01$, $\left.{ }^{* * *} P<0.001,{ }^{* * *} P<0.0001\right)$. Scale bar, $30 \mathrm{~cm}$ 


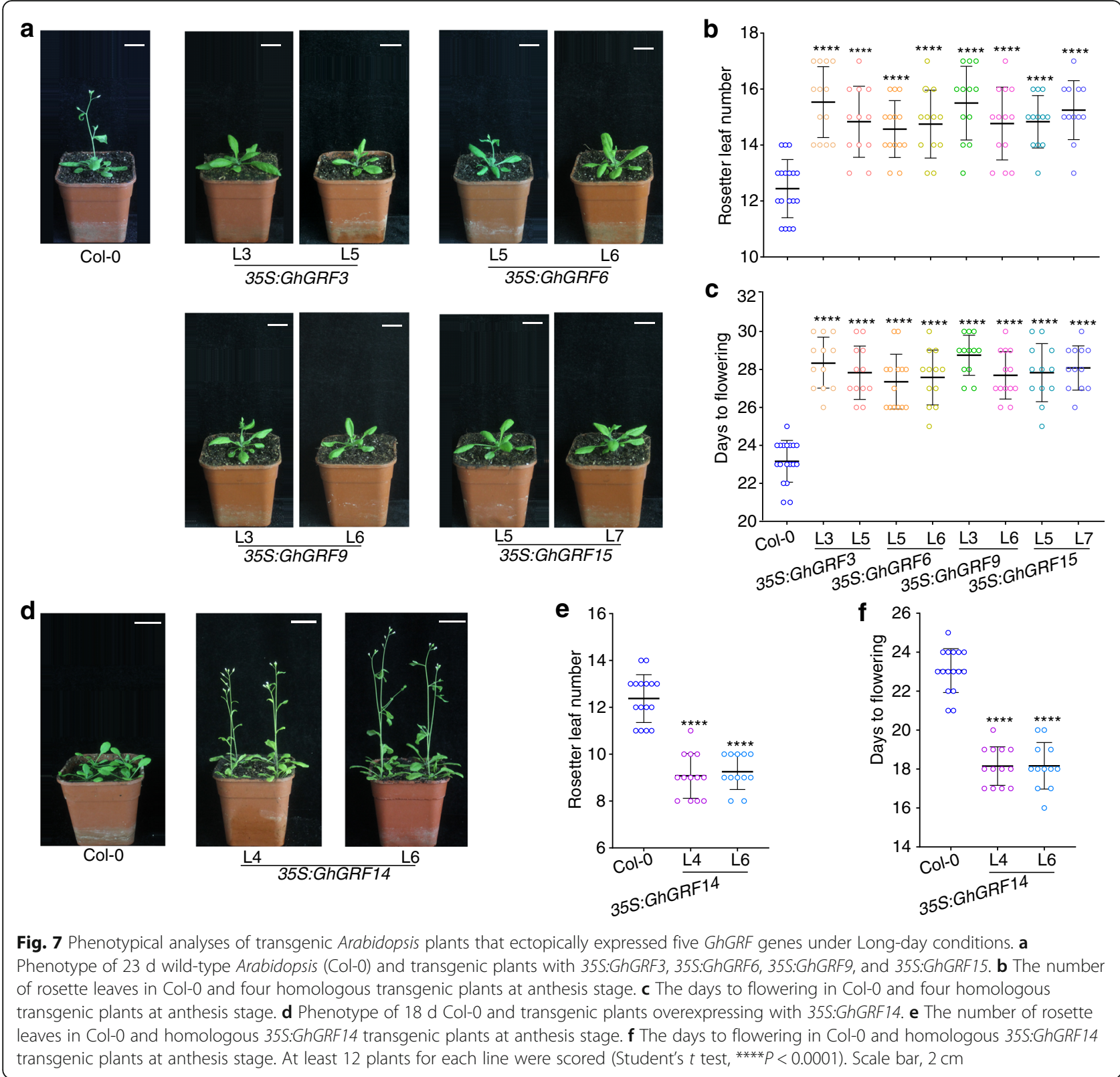

[31], populus [43], banana [10], and soybean [34]. A gene structural analysis revealed that non- $\varepsilon$ group members commonly possessed less exons and introns than $\varepsilon$ group members (Fig. 2b), which was also found in other species [31, 32, 44], and a motif analysis indicated that $\varepsilon$ and non- $\varepsilon$ groups had different motif structures, which suggested their functional diversity (Fig. 2c).

Some GRF genes formed more than one syntenic gene pair, such as GhGRF4-A and GhGRF15-A, which implied they played vital roles in evolution (Fig. 3 and Additional file 7: Table S5). The number of duplicated gene pairs in upland cotton was more than that in diploid cotton. This was related to the expansion of GRF genes in G. hirsutum, which had all undergone purifying selection
(Additional file 8: Table S6 and Additional file 9: Fig. S3a). Putative cis-elements of GRF genes in four Gossypium species participated in various responses, suggesting their functional diversity (Additional file 10: Fig. S4).

Expression profiles revealed that GhGRFs were differentially expressed in all of the investigated tissues (Fig. 4a). In total, 15 GhGRF genes were highly expressed in all the tested tissues, followed by nine GhGRF genes, suggesting that these genes participated in the whole process of cotton growth and development. Seven GhGRF genes were expressed lower or not expressed in some tissues. Specially, GhGRF14-A was highly expressed in roots, stems, petals, and ovules. In addition, some GhGRFs exhibited tissue-specific expression, such 
as GhGRF6-A/D, GhGRF8-A, and GhGRF14-A. This phenomenon also existed in some 14-3-3 genes of other plants. The expression of General regulatory factor1-Gbox factor 14-3-3 homolog isoform chi (GRF1-GF14x) from Arabidopsis has been detected in roots, flowers, siliques, and imbibed seeds, but not in leaves or cotyledons [3]. In switchgrass (Panicum virgatum), PvGF14a is expressed highly in lignified organs, while $P \nu G F 14 r$ is highly expressed in the inflorescence meristem and florets of inflorescence [45]. In grape, VviGRF12 shows high expression levels in some floral organs [16]. The diversity of the GhGRF expression levels suggested that functional differentiation may have emerged during evolution.

The diversified ternary complexes formed by GhFT, GhFD, and each GRF protein in cotton

The 14-3-3 proteins bind to flowering time regulatory proteins, such as FT [46-48] and CONSTANS [8]. GhFT localizes to the cytoplasm and nucleus, and FT interacts with FD in the nucleus $[49,50]$. In this study, we determined that GhGRF3/6/9/14/15 interacted with GhFT in the cytoplasm and nucleus (Fig. 5d), whereas they interacted with GhFD in the nucleus (Fig. 5e). The results indicated that GhFT, GhFD, and individual GhGRF proteins form different FACs in the nucleus. The formation of FACs has been reported in other species. In rice, a 14-3-3 protein interacts with Hd3a in the cytoplasm and is translocated to the nucleus where it binds OsFD to form a FAC. If OsFD1 is recruited, then the function of FT-14-3-3-FD1 is to promote flowering, while if OsFD2 is recruited, then the FAC plays a role in rice leaf development [22]. In Arabidopsis, the FT protein binds to the 14-3-3 and FD proteins to form an active FT-14-3-3-FD complex that promotes flowering [20]. In potato (Solanum tuberosum), StSP6A, an Hd3a homo$\log$, and StFDL1, a potato FD-like protein, interact with St14-3-3 s in stolon tips to form FAC-like complexes that initiate tuber formation [51]. The multifunctionality of FACs provides a direction to further study the functional diversity of 14-3-3 genes. Moreover, Y2H experiments confirmed that all the identified GhGRF proteins interacted with GhFT (Additional file 13: Fig. S6), suggesting that GhGRF proteins interact with GhFT and GhFD to form FACs that exercise diverse functions. This hypothesis needs to be further studied.

\section{FACs formed through GRFs either promote or delay flowering in cotton}

The FAC composed of florigen FT, 14-3-3 protein, and FD promotes flowering by activating downstream target genes [7, 20]. Here, we showed that upland cotton GhGRF3/6/9/14/15 formed five FACs with GhFT and GhFD in the nucleus and that the GhGRF3/6/9/15 silencing in cotton promoted the expressions of GhAP1 and
GhSOC1, resulting in early flowering. In contrast, GhGRF14 silencing suppressed the expressions of GhAP1 and GhSOC1, resulting in late flowering (Fig. 6 and Additional file 14: Fig. S7). Moreover, the overexpression of GhGRF3/6/9/15 inhibited the expression of AtAP1 and AtSOC1, causing late flowering, while GhGRF14 activated AtAP1 and AtSOC1 and promoted early flowering under LD conditions (Fig. 7 and Additional file 15: Fig. S8). These data suggested that GhGRFs, as components of the FACs, were essential for controlling flowering time in cotton.

Our model of the ternary FACs composed of GhFT, GhFD, and each of the five GhGRF proteins implies that the roles of the FACs in regulating flowering were determined by the GhGRF protein present (Fig. 8). When the interaction occurred between GhFT, GhFD, and GhGRF3/6/9/15, FACs inhibited flowering by downregulating the expression of flower identity genes, such as $A P 1$ and SOC1. However, when the FAC was formed by the interaction between GhFT, GhFD, and GhGRF14, the transcription of the $A P 1$ and SOC1 homologues were upregulated to promote flowering. Our findings suggested that GhGRFs regulate flowering time by forming FACs with GhFT and GhFD. In summary, we determined that FACs in cotton function as either activators or repressors of flowering, and we revealed a mechanism of flowering regulation in G. hirsutum.

\section{Conclusions}

In this study, 82 GRF genes were identified from four cottons (Gossypium spp.) by genome-wide analyses. All the GRF proteins contained the conserved 14-3-3 domain and were classified into two groups on the basis of their phylogenetic relationships with GRFs in other plant species. Their structural characteristics, evolution, cisacting elements, and expression profiles revealed the conservation and diversity of GRF gene functions in cotton. Furthermore, we showed that GhGRFs interact with GhFT and GhFD proteins to form FACs in the nucleus, which function either in promoting or inhibiting flowering by regulating the expression of floral meristemidentity genes, such as $A P 1$ and SOC1 homologues. The results indicate the functional diversification of FACs in cotton and lay a solid foundation for further studies on the functional mechanisms of GhGRFs.

\section{Methods \\ Plant materials}

Cotton seeds (G. hirsutum L. cv. XLZ 33) were fieldgrown under natural conditions during the summer of 2019 in Shihezi (Xinjiang, China). The seed sterilization and cultivation methods, as well as the growth conditions for A. thaliana Columbia (Col-0) and transgenic plants used in this study, were as previously described 
a

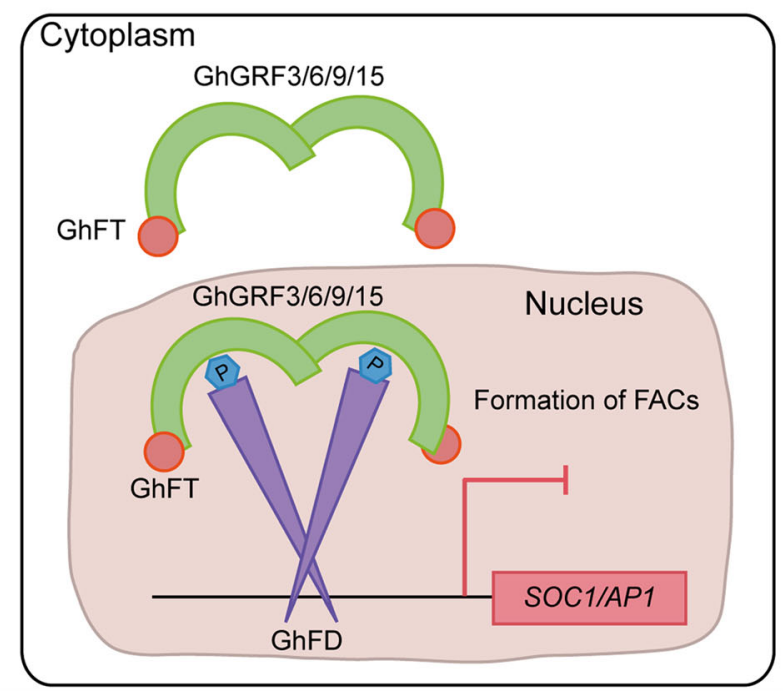

b

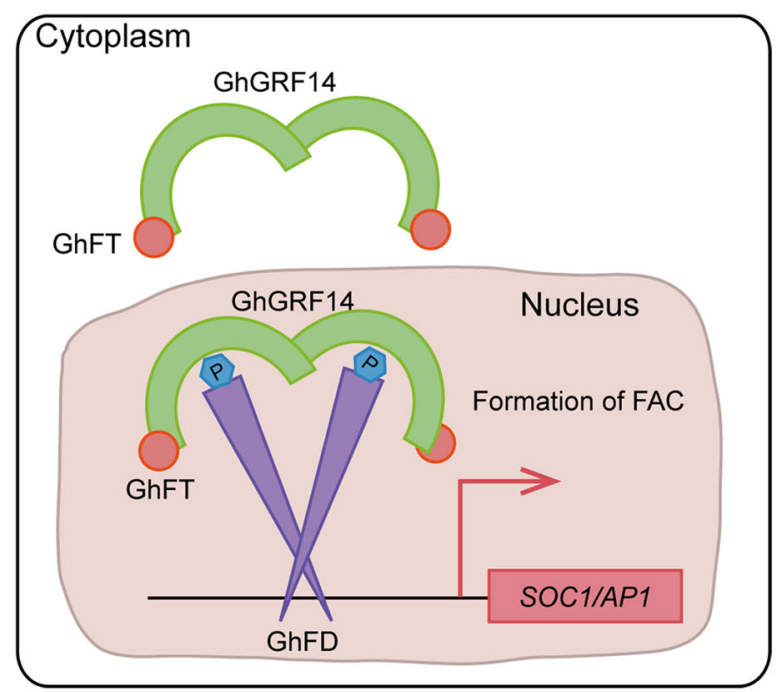

Fig. 8 Schematic diagram of the FACs functioning in flowering regulation in cotton. a The FACs formed by GhFT, GhFD, and each GhGRF protein, such as GhGRF3, 6, 9, and 15, inhibit the expression of AP1 and SOC1 homologues, causing late flowering. b The FAC formed by GhFT, GhFD, and GhGRF14 promotes the expression of AP1 and SOC1 homologues, resulting in early flowering

$[49,52]$. Collection of plant or seed specimens complied with relevant institutional, national, and international guidelines and legislation.

For gene expression analyses, the fresh leaves of Col-0 and the transgenic lines were harvested under LD conditions in a plant growth chamber. All collected samples were frozen immediately in liquid nitrogen and stored at $-80^{\circ} \mathrm{C}$.

\section{RNA extraction and qRT-PCR analyses}

Total RNA for each sample was isolated using the RNAprep pure Plant Kit (Tiangen, Beijing, China) and treated with RNase-free DNase (Tiangen) in accordance with the manufacturer's protocol. The quality, quantity, and integrity of the total RNA extracted were assessed as previously described [49]. Total RNA was reversed transcribed into cDNA using the Superscript First-Strand Synthesis System (Invitrogen, Carlsbad, CA, USA). The qRT-PCR using the SYBR Green Master Mixture (CWBIO, Beijing, China) on an Applied Biosystems 7500 Fast Real-Time PCR System (Life Technologies, Foster City, CA, USA) were performed as previously described [53]. The PCR amplification system and program were as described previously [52]. Primers used in this study are listed in Additional file 16: Table S8. All qRT-PCR assays were repeated three times as independent biological replicates. Relative gene expression levels were calculated using the $2^{-\Delta \mathrm{Ct}}$ method [54].

\section{Identification of the GRF gene family in cotton}

The $\mathrm{A}_{1}$ genome of diploid G. herbaceum [55], the $\mathrm{A}_{2}$ genome of diploid G. arboreum [56], the (AD) $)_{1}$ tetraploid genome of G. hirsutum [57] and the $\mathrm{D}_{5}$ genome of diploid G. raimondii [58] were downloaded from Cottongen (https://www.cottongen.org/). The HMM document, downloaded from Pfam database (http://pfam.sanger.ac.uk/), was used to identify the GRF genes in genome database of four cotton species using Simple HMM Search in TBtools [59]. All predicted GRF protein sequences were submitted to NCBI Batch CD-Search (http://www.ncbi.nlm.nih.gov/ Structure/cdd/wrpsb.cgi) [60] and Pfam (https://pfam.xfam. org) [61] to confirm the 14-3-3 domain. Partial and redundant sequences were all manually removed. MapInspect software (http://mapinspect.software.informer.com/) was used to locate those genes on chromosomes. Furthermore, the molecular weight and isoelectric point of GRF proteins were determined using ExPASy (http://web.expasy.org/ compute_pi/) [62].

\section{Multiple sequence alignment and phylogenetic analysis}

The amino acid sequences of the GRF family members identified in cotton were aligned using the CLUSTALX program [63]. The full-length amino acid sequences of 143-3 s derived from Arabidopsis, rice, P. trichocarpa, B. distachyon, foxtail millet, and cotton were used for phylogenetic analysis using MEGA5.1 [36] by the Neighbor-Joining method with 1000 bootstrap replications. Finally, the online tool Evolview (http://www.evolgenius.info/evolview/) [64], was used to clarify and construct the phylogenetic tree.

Gene structure, conserved motif, and promoter analyses The exon-intron structures of the GRF genes were generated using the Gene Structure Display Server version 
2.0 (http://gsds.cbi.pku.edu.cn/) [65]. MEME software (http://meme-suite.org/tools/meme) [37] was used to identify conserved cotton GRF protein motifs. It also determined that the maximum number of motifs was seven and optimum width was from 6 to 50 . The predicted motifs in cotton GRF proteins were further annotated using the InterPro database (http://www.ebi.ac.uk/ interpro/) [38]. The PlantCare database (http:// bioinformatics.psb.ugent.be/webtools/plantcare/html/) [66] was used to search potential cis-regulatory elements in the $2.0-\mathrm{kb}$ promoter region.

\section{Syntenic and gene duplication analyses}

To display the syntenic relationship of GRF genes between G. hirsutum and the other three analyzed cottons species, syntenic maps were constructed using the Multiple Synteny Plot software from TBtools [59]. BLASTp search with E-value $<1 \times 10^{-5}$ were performed to identify duplicated GRF genes. To be defined as duplicated genes, the following two criteria had to be met: the aligned region of two sequences covered $>80 \%$ of the longer sequence and the identity of the aligned regions $>90 \%$ [67]. The $K a$ and $K s$ substitution rates of orthologous and homologous pairs of GRF genes were calculated using DnaSP software [68]. The selective pressure was analyzed using $\mathrm{Ka} / \mathrm{Ks}$ ratio.

\section{Expression analyses of the GhGRF genes using RNA-Seq} To obtain the expression profiles of GhGRF genes, RNA-seq data of G. hirsutum TM-1 were downloaded from NCBI (https://www.ncbi.nlm.nih.gov/bioproject/ PRJNA490626) [41]. The expression levels of GhGRF genes in 15 tissues were represented by log-transformed FPKM $\left(\log _{2}[\mathrm{FPKM}+1]\right)$ values. The $\mathrm{R}$ package "pheatmap" was used to generate the expression patterns of the GhGRF genes in these tissues.

\section{Plasmid construction and genetic transformation of Arabidopsis}

The coding sequences of the five GhGRF genes were independently cloned into the pMD19-T vector, and positive plasmids containing each gene, as identified by sequences analyses, were then introduced into the plant binary vector $p C A M B I A 2300-35 S-O C S$ [49] to generate 35S:GhGRF3, 35S:GhGRF6, 35S:GhGRF9, 35S:GhGRF14, and 35S:GhGRF15. All of the constructs were introduced independently into Agrobacterium tumefaciens GV3101 and transformed into A. thaliana Col-0 using the floral dip method [69]. Flowering times were determined by counting the number of rosette leaves per plant and the days it took for the first flower to bloom.

\section{$\mathrm{Y} 2 \mathrm{H}$ assays}

The yeast cloning vectors, pGBKT7 and pGADT7, and the yeast strain $\mathrm{AH} 109$ used in the $\mathrm{Y} 2 \mathrm{H}$ assays were obtained from Clontech (Mountain View, CA, USA). The BD-GhFT vector used in this study was previously published [70]. The coding sequences of GhFD and 17 GhGRFs were amplified by PCR using gene-specific primers (Additional file 16: Table S8) and then cloned independently into the pMD19$\mathrm{T}$ vector (TaKaRa, Dalian, China) following the manufacturer's instructions. All of the plasmids were confirmed by sequence analysis, and then GhFD and 17 GhGRFs were fused to the GAL4 activation domain of pGADT7 to generate $A D-G h F D$ and $A D-G h G R F$ prey constructs. The $\mathrm{Y} 2 \mathrm{H}$ assays were performed in accordance with a method described previously [70].

\section{BiFC assays}

The coding regions of GhFD and five GhGRFs were amplified using gene-specific primers (Additional file 16: Table S8) and cloned independently into the pDONRZeo vector (Invitrogen) using BP reaction, and then, they were fused to the N-terminus or C-terminus of the PVYNE or PSCY CE vector, respectively [71], using the LR reaction, to generate $n Y F P-G h F D$ and $c Y F P-G h G R F$ s. The $n Y F P-G h F T$ vector used in this study was previously published [70]. The $n Y F P-G h F D, n Y F P-G h F T$, and $c Y F P-G h G R F$ plasmids were each introduced into A. tumefaciens GV3101 cells, which were then infiltrated into $N$. benthamiana leaves for transient expression as described previously [70].

\section{VIGS assays}

For the VIGS assay, each GhGRF fragment was cloned by RT-PCR using gene-specific primers (Additional file 16: Table S8) and inserted separately into the $p T R V 2$ vectors to generate the $p T R V 2: G h G R F$ constructs. Each $p T R V: G h G R F$ plasmid was introduced into A. tumefaciens strain GV3101, and infiltrated into cotyledons of G. hirsutum L. cv. XLZ 33 as previously described [70, 72].

\section{Abbreviations}

GRF: GENERAL REGULATORY FACTOR; FT: FLOWERING LOCUS T; FAC: florigen activation complex; AP1: APETALA1; SOC1: SUPPRESSOR OF OVEREXPRESSION OF CONSTANS 1; LD: long-day; GF14s: G-box Factor 14-3-3 homologs; Y2H: yeast two-hybrid; BiFC: bimolecular fluorescence complementation; MeJA: methyl jasmonate; qRT-PCR: quantitative real-time PCR; LT: SD/-TrpLeu; LTHA: SD/-Trp-Leu-His-Ade; DPA: day post-anthesis; HMM: Hidden Markov Model; FPKM: represented by fragments per kilobase million; Ka: non-synonymous; Ks: synonymous; VIGS: virus-induced gene silencing

\section{Supplementary Information}

The online version contains supplementary material available at https://doi. org/10.1186/s12870-021-02923-9.

Additional file 1: Table S1. Nomenclature of the GRF genes from G. hirsutum. 
Additional file 2: Table S2. Predicted G. herbaceum, G. arboreum, G. raimondii, and $G$. hirsutum GRF proteins with genome identifiers.

Additional file 3: Table S3. Features of the GRF genes identified from G. herbaceum, G. arboreum, G. hirsutum, and G. raimondii. (XLSX 14 kb)

Additional file 4: Fig. S1. Chromosomal distributions of the Gossypium spp. GRF genes. (a) G. herbaceum. (b) G. arboreum. (c) G. hirsutum. (d) G. raimondii. Chromosomal locations were shown from top to bottom on corresponding chromosomes according to cotton genome annotation.

Additional file 5: Fig. S2. Multiple amino acid sequence alignment of cotton GRF proteins. Amino acid sequence alignment of $82 \mathrm{GRF}$ proteins from G. herbaceum, G. arboreum, G. hirsutum, and G. raimondii. Nine ahelices were marked as a1-a9.

Additional file 6: Table S4. Seven conserved amino acid motifs and annotation of cotton GRF proteins.

Additional file 7: Table S5. Syntenic gene pairs between G. hirsutum and other three cotton species.

Additional file 8: Table S6. The duplicated GRF gene pairs from G. herbaceum, G. arboreum, G. hirsutum, and G. raimondii, respectively.

Additional file 9: Fig. S3. Distributions of $\mathrm{Ka} / \mathrm{Ks}$ values of cotton GRF gene pairs. (a) Ka/Ks ratios for paralogous genes in four cotton species. (b) Boxplot showing the Ka/Ks ratios for orthologous genes among cotton genomes. The center line in each box indicates the median, and the box limits indicate the upper and lower quartiles of divergence.

Additional file 10: Fig. S4. The percentage of various responses about cis-acting elements on 2.0-kb promoter of the GRF genes in (a) $G$ herbaceum, (b) G. arboreum, (c) G. hirsutum, and (d) G. raimondii.

Additional file 11: Fig. S5. Information of type, quantity, and location of various response elements in cotton.

Additional file 12: Table S7. The FPKM value of GhGRFs in different tissues.

Additional file 13: Fig. S6. Interaction of GhFT and each GhGRF protein. Plasmids transformed into $\mathrm{AH} 109$ yeast strains were screened on the -LT and -LTHA medium.

Additional file 14: Fig. S7. Flowering times and the expression levels of the floral-meristem identity genes in the control and GhGRF silencing plants. (a-e) Statistics of flowering times in the control and GhGRF silencing plants. qRT-PCR analysis of the expression levels of GhAP1

(Gh_D13G0878) (f-j) and GhSOC1 (Gh_A11G0755) (k-o). A cotton Ubiquitin7 (GhUBQ7, GenBank accession no. DQ116441) gene was used as an in ternal reference gene. Values are means $\pm S D(n=3)$. Asterisks indicate significant differences between control TRV:00 and TRV:GhGRFs silencing lines (Student's $t$ test, ${ }^{*} P<0.05$, ${ }^{* *} P<0.01,{ }^{* * *} P<0.001$, ${ }^{* * * *} P<0.0001$ ).

Additional file 15: Fig. S8. $q R T-P C R$ expression analysis of GhGRF, AtSOC1, and AtAP1. ACT2 (At3g18780) was used as an internal reference transcript. Values are means $\pm S D(n=3)$. Asterisks indicate significant differences between Col-0 and the 35S:GhGRFs transgenic lines (Student's $t$ test, ${ }^{* *} P<0.01,{ }^{* * *} P<0.001$, ${ }^{* * * *} P<0.0001$ )

Additional file 16: Table S8. PCR primers used in this study.

\section{Acknowledgements}

Not applicable.

\section{Authors' contributions}

NS carried out the identification of gene family and the molecular biological studies. $\mathrm{HL}$ performed the BiFC, Y2H and VIGS experiments. BM participated in the gene expression and GRT-PCR analyses. LZ planted cotton materials in the field and collected samples. XH and YS conceived and designed the study. $\mathrm{XH}$ and NS drafted the manuscript. All authors read and approved the final manuscript.

\section{Funding}

This research was supported by the National Natural Science Foundation of China (No. 31860393, 31360366), the Academic Leaders of Anhui University of Science and Technology Introduction Starting Fund (No. NXYJ202001), and Research and Innovation Project of Postgraduates in Xinjiang Uygur Autonomous Region (No. XJ2019G079).

\section{Availability of data and materials}

All data generated or analysed during this study are included in this article [and its supplementary information files].

\section{Declarations}

Ethics approval and consent to participate

Not applicable.

\section{Consent for publication}

Not applicable.

\section{Competing interests}

The authors declare no conflict of interests.

\section{Author details}

${ }^{1}$ The Key Laboratory of Oasis Eco-Agriculture, College of Agriculture, Shihezi University, Shihezi 832000, China. 'Special Plant Genomics Laboratory, College of Life Sciences, Shihezi University, Shihezi 832000, China. ${ }^{3}$ Center for Crop Biotechnology, College of Agriculture, Anhui Science and Technology University, Fengyang 233100, China. ${ }^{4}$ Plant Genomics \& Molecular Improvement of Colored Fiber Laboratory, College of Life Sciences and Medicine, Zhejiang Sci-Tech University, Hangzhou 310016, Zhejiang, China.

Received: 19 January 2021 Accepted: 8 March 2021

Published online: 31 March 2021

\section{References}

1. Aitken A, Collinge DB, van Heusden BP, Isobe T, Roseboom PH, Rosenfeld G, Soll J. 14-3-3 proteins: a highly conserved, widespread family of eukaryotic proteins. Trends Biochem Sci. 1992;17(12):498-501. https://doi.org/10.1016/ 0968-0004(92)90339-B.

2. Rooney MF, Ferl RJ. Sequences of three Arabidopsis general regulatory factor genes encoding GF14 (14-3-3) proteins. Plant Physiol. 1995;107(1):283-4. https://doi.org/10.1104/pp.107.1.283.

3. Daugherty CJ, Rooney MF, Miller PW, Ferl RJ. Molecular organization and tissue-specific expression of an Arabidopsis 14-3-3 gene. Plant Cell. 1996;8(8): 1239-48. https://doi.org/10.1105/tpc.8.8.1239.

4. Wu K, Rooney MF, Ferl RJ. The Arabidopsis 14-3-3 multigene family. Plant Physiol. 1997;114(4):1421-31. https://doi.org/10.1104/pp.114.4.1421.

5. Yaffe MB, Rittinger K, Volinia S, Caron PR, Aitken A, Leffers H, Gamblin SJ, Smerdon SJ, Cantley LC. The structural basis for 14-3-3: phosphopeptide binding specificity. Cell. 1997;91(7):961-71. https://doi.org/10.1016/S00928674(00)80487-0.

6. Ottmann C, Marco S, Jaspert N, Marcon C, Schauer N, Weyand M, Vandermeeren C, Duby G, Boutry M, Wittinghofer A, Rigaud JL, Oecking C. Structure of a 14-3-3 coordinated hexamer of the plant plasma membrane $\mathrm{H}+-$ ATPase by combining X-ray crystallography and electron cryomicroscopy. Mol Cell. 2007;25(3):427-40. https://doi.org/10.1016/j. molcel.2006.12.017.

7. Taoka K, Ohki I, Tsuji H, Furuita K, Hayashi K, Yanase T, Yamaguchi M, Nakashima C, Purwestri YA, Tamaki S, Ogaki Y, Shimada C, Nakagawa A, Kojima C, Shimamoto K. 14-3-3 proteins act as intracellular receptors for rice Hd3a florigen. Nature. 2011;476(7360):332-5. https://doi.org/10.1038/nature1 0272

8. Mayfield JD, Folta KM, Paul AL, Ferl RJ. The 14-3-3 proteins $\mu$ and $u$ influence transition to flowering and early phytochrome response. Plant Physiol. 2007;145(4):1692-702. https://doi.org/10.1104/pp.107.108654.

9. Radwan O, Wu X, Govindarajulu M, Libault M, Neece DJ, Oh MH, Berg RH, Stacey G, Taylor CG, Huber SC, Clough SJ. 14-3-3 proteins SGF14C and SGF14I play critical roles during soybean nodulation. Plant Physiol. 2012; 160(4):2125-36. https://doi.org/10.1104/pp.112.207027.

10. Li MY, Ren LC, Xu BY, Yang XL, Xia QY, He PP, Xiao SS, Guo AP, Hu W, Jin $Z Q$. Genome-wide identification, phylogeny, and expression analyses of the 14-3-3 family reveal their involvement in the development, ripening, and abiotic stress response in banana. Front Plant Sci. 2016;7:1442

11. Liu Q, Zhang SH, Liu B. 14-3-3 proteins: macro-regulators with great potential for improving abiotic stress tolerance in plants. Biochem Biophys Res Commun. 2016;477(1):9-13. https://doi.org/10.1016/j.bbrc.2016.05.120.

12. Yan JQ, He CX, Wang J, Mao ZH, Holaday SA, Allen RD, Zhang H. Overexpression of the Arabidopsis 14-3-3 protein GF14 lambda in cotton 
leads to a "stay-green" phenotype and improves stress tolerance under moderate drought conditions. Plant Cell Physiol. 2004;45(8):1007-14. https:// doi.org/10.1093/pcp/pch115.

13. Campo S, Peris-Peris C, Montesinos L, Peñas G, Messeguer J, San SB. Expression of the maize ZmGF14-6 gene in rice confers tolerance to drought stress while enhancing susceptibility to pathogen infection. J Exp Bot. 2012;63(2):983-99. https://doi.org/10.1093/jxb/err328.

14. He YC, Wu JJ, Lv B, Li J, Gao ZP, Xu WF, Baluška F, Shi WM, Shaw PC, Zhang $\mathrm{JH}$. Involvement of 14-3-3 protein GRF9 in root growth and response under polyethylene glycol-induced water stress. J Exp Bot. 2015;66(8):2271-81. https://doi.org/10.1093/jxb/erv149.

15. Yao Y, Du Y, Jiang L, Liu JY. Molecular analysis and expression patterns of the 14-3-3 gene family from Oryza sativa. J Biochem Mol Biol. 2007;40(3): 349-57. https://doi.org/10.5483/bmbrep.2007.40.3.349.

16. Cheng C, Wang Y, Chai FM, Li SH, Xin HP, Liang ZC. Genome-wide identification and characterization of the 14-3-3 family in Vitis vinifera $\mathrm{L}$. during berry development and cold- and heat-stress response. BMC Genomics. 2018;19(1):579.

17. Pnueli L, Carmel-Goren L, Hareven D, Gutfinger T, Alvarez J, Ganal M, Zamir D, Lifschitz E. The SELF-PRUNING gene of tomato regulates vegetative to reproductive switching of sympodial meristems and is the ortholog of CEN and TFL1. Development. 1998;125(11):1979-89.

18. Pnueli L, Gutfinger T, Hareven D, Ben-Naim O, Ron N, Adir N, Lifschitz E. Tomato SP-interacting proteins define a conserved signaling system that regulates shoot architecture and flowering. Plant Cell. 2001;13(12):2687-702. https://doi.org/10.1105/tpc.010293.

19. Li BJ, Xiao GH, Luo KS, Wang ZY, Mao BZ, Lin XC, Guo XQ. Overexpression of PVGF14C from Phyllostachys violascens delays flowering time in transgenic Arabidopsis. Front Plant Sci. 2018;9:105. https://doi.org/10.3389/fpls.2018.001 05.

20. Golembeski GS, Imaizumi T. Photoperiodic regulation of florigen function in Arabidopsis thaliana. Arabidopsis Book. 2015;13:e0178. https://doi.org/10.11 99/tab.0178.

21. Abe M, Kobayashi Y, Yamamoto S, Daimon Y, Yamaguchi A, Ikeda Y, Ichinoki H, Notaguchi M, Goto K, Araki T. FD, a bZIP protein mediating signals from the floral pathway integrator FT at the shoot apex. Science. 2005;309(5737): 1052-6. https://doi.org/10.1126/science.1115983.

22. Tsuji H, Nakamura $H$, Taoka K, Shimamoto K. Functional diversification of FD transcription factors in rice, components of florigen activation complexes. Plant Cell Physiol. 2013;54(3):385-97. https://doi.org/10.1093/pcp/pct005.

23. Saha S, Jenkins JN, Wu JX, McCarty JC, Gutiérrez OA, Percy RG, Cantrell RG, Stelly DM. Effects of chromosome-specific introgression in upland cotton on fiber and agronomic traits. Genetics. 2006;172(3):1927-38. https://doi.org/1 0.1534/genetics.105.053371.

24. Shi HY, Wang XL, Li DD, Tang WK, Wang H, Xu WL, Li XB. Molecular characterization of cotton $14-3-3 L$ gene preferentially expressed during fiber elongation. J Genet Genomics. 2007;34(2):151-9. https://doi.org/10.1016/S1 673-8527(07)60016-2

25. Zhang ZT, Zhou Y, Li Y, Shao SQ, Li BY, Shi HY, Li XB. Interactome analysis of the six cotton 14-3-3s that are preferentially expressed in fibres and involved in cell elongation. J Exp Bot. 2010;61(12):3331-44. https://doi.org/1 0.1093/jxb/erq155.

26. Sun GL, Xie FL, Zhang BH. Transcriptome-wide identification and stress properties of the 14-3-3 gene family in cotton (Gossypium hirsutum L.). Funct Integr Genomics. 2011;11(4):627-36. https://doi.org/10.1007/s10142011-0242-3.

27. Zhou Y, Zhang ZT, Li M, Wei XZ, Li XJ, Li BY, Li XB. Cotton (Gossypium hirsutum) 14-3-3 proteins participate in regulation of fibre initiation and elongation by modulating brassinosteroid signalling. Plant Biotechnol J. 2015;13(2):269-80. https://doi.org/10.1111/pbi.12275.

28. Zhang ZN, Ge XY, Luo XL, Wang P, Fan Q, Hu G, Xiao JL, Li FG, Wu JH. Simultaneous editing of two copies of Gh14-3-3d confers enhanced transgene-clean plant defense against Verticillium dahliae in allotetraploid upland cotton. Front Plant Sci. 2018;9:842. https://doi.org/10.3389/fpls.2018. 00842.

29. DeLille JM, Sehnke PC, Ferl RJ. The Arabidopsis 14-3-3 family of signaling regulators. Plant Physiol. 2001;126(1):35-8. https://doi.org/10.1104/pp.126.1.35.

30. Rosenquist M, Alsterfjord M, Larsson C, Sommarin M. Data mining the Arabidopsis genome reveals fifteen 14-3-3 genes. Expression is demonstrated for two out of five novel genes. Plant Physiol. 2001;127(1): 142-9. https://doi.org/10.1104/pp.127.1.142.
31. Chevalier D, Morris ER, Walker JC. 14-3-3 and FHA domains mediate phosphoprotein interactions. Annu Rev Plant Biol. 2009;60(1):67-91. https:// doi.org/10.1146/annurev.arplant.59.032607.092844.

32. Chen F, Li Q, Sun LX, He ZH. The rice 14-3-3 gene family and its involvement in responses to biotic and abiotic stress. DNA Res. 2006;13(2): 53-63. https://doi.org/10.1093/dnares/dsl001.

33. Qin C, Cheng LM, Shen JQ, Zhang YH, Cao HM, Lu D, Shen CJ. Genomewide identification and expression analysis of the 14-3-3 family genes in Medicago truncatula. Front Plant Sci. 2016;7:320.

34. Wang YB, Ling L, Jiang ZF, Tan WW, Zhaojun Liu ZJ, Wu LC, Yuanling Zhao YL, Xia SY, Ma J, Wang GG, Li WB. Genome-wide identification and expression analysis of the 14-3-3 gene family in soybean (Glycine max). Peer. 2019;7:e7950. https://doi.org/10.7717/peerj.7950.

35. Liu JL, Jiang $C Y$, Kang L, Zhang HC, Song Y, Zou ZR, Zheng WJ. Overexpression of a 14-3-3 protein from foxtail millet improves plant tolerance to salinity stress in Arabidopsis thaliana. Front Plant Sci. 2020;11:449. https:// doi.org/10.3389/fpls.2020.00449.

36. Tamura K, Peterson D, Peterson N, Stecher G, Nei M, Kumar S. MEGA5: molecular evolutionary genetics analysis using maximum likelihood, evolutionary distance, and maximum parsimony methods. Mol Biol Evol. 2011;28(10):2731-9. https://doi.org/10.1093/molbev/msr121.

37. Bailey TL, Johnson J, Grant CE, Noble WS. The MEME suite. Nucleic Acids Res. 2015;43(W1):W39-49. https://doi.org/10.1093/nar/gkv416.

38. Mitchell AL, Attwood TK, Babbitt PC, Blum M, Bork P, Bridge A, Brown SD, Chang HY, el-Gebali S, Fraser MI, Gough J, Haft DR, Huang H, Letunic I, Lopez R, Luciani A, Madeira F, Marchler-Bauer A, Mi H, Natale DA, Necci M, Nuka G, Orengo C, Pandurangan AP, Paysan-Lafosse T, Pesseat S, Potter SC, Qureshi MA, Rawlings ND, Redaschi N, Richardson L, Rivoire C, Salazar GA, Sangrador-Vegas A, Sigrist CJA, Sillitoe I, Sutton GG, Thanki N, Thomas PD, Tosatto SCE, Yong SY, Finn RD. InterPro in 2019: improving coverage, classification and access to protein sequence annotations. Nucleic Acids Res. 2019:47(D1):D351-60. https://doi.org/10.1093/nar/gky1100.

39. Long $\mathrm{M}$, Langley $\mathrm{CH}$. Natural selection and the origin of jingwei, a chimeric processed functional gene in drosophila. Science. 1993;260(5104):91-5. https://doi.org/10.1126/science.7682012.

40. Lynch M, Conery JS. The evolutionary fate and consequences of duplicate genes. Science. 2000;290(5494):1151-5. https://doi.org/10.1126/science.290. 5494.1151.

41. Hu Y, Chen JD, Fang L, Zhang ZY, Ma W, Niu YC, Ju LZ, Deng JQ, Zhao T, Lian JM, Baruch K, Fang D, Liu X, Ruan YL, Rahman MU, Han J, Wang K, Wang Q, Wu H, Mei G, Zang Y, Han Z, Xu C, Shen W, Yang D, Si Z, Dai F, Zou L, Huang F, Bai Y, Zhang Y, Brodt A, Ben-Hamo H, Zhu X, Zhou B, Guan X, Zhu S, Chen X, Zhang T. Gossypium barbadense and Gossypium hirsutum genomes provide insights into the origin and evolution of allotetraploid cotton. Nat Genet. 2019; 51(4):739-48. https:/doi.org/10.1038/s41588-019-0371-5.

42. Jones DH, Ley S, Aitken A. Isoforms of 14-3-3 protein can form homo- and heterodimers in vivo and in vitro: implications for function as adapter proteins. FEBS Lett. 1995;368(1):55-8. https://doi.org/10.1016/0014-5793 (95)00598-4.

43. Tian FX, Wang T, Xie YL, Zhang J, Hu JJ. Genome-wide identification, classification, and expression analysis of 14-3-3 gene family in Populus. PLoS One. 2015;10(4):e0123225. https://doi.org/10.1371/journal.pone.0123225.

44. Li RH, Jiang XT, Jin DH, Dhaubhadel S, Bian SM, Li XY. Identification of 14-33 family in common bean and their response to abiotic stress. PLoS One. 2015;10(11):e0142580.

45. Wu S, Yan HD, Zhang AL, Huang LK, Yin GH, Lee S. Identification and characterization of the 14-3-3 gene family in switchgrass. Genet Mol Res. 2016;15(4):gmr15048688.

46. Lifschitz E, Eviatar T, Rozman A, Shalit A, Goldshmidt A, Amsellem Z, Alvarez JP, Eshed Y. The tomato FT ortholog triggers systemic signals that regulate growth and flowering and substitute for diverse environmental stimuli. Proc Natl Acad Sci U S A. 2006;103(16):6398-403. https://doi.org/10.1073/pnas. 0601620103.

47. Corbesier L, Vincent C, Jang S, Fornara F, Fan Q, Searle I, Giakountis A, Farrona S, Gissot L, Turnbull C, Coupland G. FT protein movement contributes to long-distance signaling in floral induction of Arabidopsis. Science. 2007;316(5827):1030-3. https://doi.org/10.1126/science.1141752.

48. Tamaki S, Matsuo S, Wong HL, Yokoi S, Shimamoto K. Hd3a protein is a mobile flowering signal in rice. Science. 2007;316(5827):1033-6. https://doi. org/10.1126/science.1141753. 
49. Guo DL, Li C, Dong R, Li XB, Xiao XW, Huang XZ. Molecular cloning and functional analysis of the FLOWERING LOCUS T (FT) homolog GhFT1 from Gossypium hirsutum. J Integr Plant Biol. 2015;57(6):522-33. https://doi.org/1 $0.1111 / j i p b .12316$

50. Harig L, Beinecke FA, Oltmanns J, Muth J, Müller O, Rüping B, Twyman RM, Fischer R, Prüfer D, Noll GA. Proteins from the FLOWERING LOCUS T-like subclade of the PEBP family act antagonistically to regulate floral initiation in tobacco. Plant J. 2012;72(6):908-21. https://doi.org/10.1111/j.1365-313X.2 012.05125.x

51. Teo CJ, Takahashi K, Shimizu K, Shimamoto K, Taoka Kl. Potato tuber induction is regulated by interactions between components of a tuberigen complex. Plant Cell Physiol. 2017;58(2):365-74. https://doi.org/10.1093/pcp/ pcW197.

52. Cai DR, Liu H, Sang N, Huang XZ. Identification and characterization of CONSTANS-like (COL) gene family in upland cotton (Gossypium hirsutum L.) PLOS ONE. 2017;12(6):e0179038.

53. Sang N, Cai DR, Li C, Sun YQ, Huang XZ. Characterization and activity analyses of the FLOWERING LOCUS T promoter in Gossypium Hirsutum. Int $J$ Mol Sci. 2019:20(19):4769. https://doi.org/10.3390/ijms20194769.

54. Livak KJ, Schmittgen TD. Analysis of relative gene expression data using real-time quantitative $P C R$ and the 2(-Delta Delta $C(T))$ method. Methods. 2001;25(4):402-8. https://doi.org/10.1006/meth.2001.1262.

55. Huang G, Wu ZG, Percy RG, Bai MZ, Li Y, Frelichowski JE, Hu J, Wang K, John Z. Yu JZ and Zhu YX. Genome sequence of Gossypium herbaceum and genome updates of Gossypium arboreum and Gossypium hirsutum provide insights into cotton A-genome evolution. Nat Genet 2020;52(5):516-524, DOl: https://doi.org/10.1038/s41588-020-0607-4.

56. Li FG, Fan GY, Wang KB, Sun FM, Yuan YL, Song GL, Li Q, Ma ZY, Lu CR, Zou CS, Chen WB, Liang XM, Shang HH, Liu WQ, Shi CC, Xiao GH, Gou CY, Ye WW, Xu X, Zhang XY, Wei HL, Li ZF, Zhang GY, Wang JY, Liu K, Kohel RJ, Percy RG, Yu JZ, Zhu YX, Wang J, Yu SX. Genome sequence of the cultivated cotton Gossypium arboreum. Nat Genet. 2014;46(5):567-72. https://doi.org/10.1038/ng.2987.

57. Zhang TZ, Hu Y, Jiang WK, Fang L, Guan XY, Chen JD, Zhang JB, Saski CA, Scheffler BE, Stelly DM, Hulse-Kemp AM, Wan Q, Liu B, Liu C, Wang S, Pan M, Wang Y, Wang D, Ye W, Chang L, Zhang W, Song Q, Kirkbride RC, Chen $X$, Dennis E, Llewellyn DJ, Peterson DG, Thaxton $P$, Jones DC, Wang $Q, X u X$, Zhang H, Wu H, Zhou L, Mei G, Chen S, Tian Y, Xiang D, Li X, Ding J, Zuo Q, Tao L, Liu Y, Li J, Lin Y, Hui Y, Cao Z, Cai C, Zhu X, Jiang Z, Zhou B, Guo W, Li R, Chen ZJ. Sequencing of allotetraploid cotton (Gossypium hirsutum L. acc. TM-1) provides a resource for fiber improvement. Nat Biotechnol. 2015; 33(5):531-7. https://doi.org/10.1038/nbt.3207.

58. Wang KB, Wang ZW, Li FG, Ye WW, Wang JY, Song GL, Yue Z, Cong L, Shang HH, Zhu SL, Zou CS, Li Q, Yuan YL, Lu CR, Wei HL, Guo CY, Zheng ZQ, Yin Y, Zhang XY, Liu K, Wang B, Song C, Shi N, Kohel RJ, Percy RG, Yu JZ, Zhu YX, Wang J, Yu SX. The draft genome of a diploid cotton Gossypium raimondii. Nat Genet. 2012;44(10):1098-103. https://doi.org/10.1038/ng.2371.

59. Chen CJ, Chen H, Zhang Y, Thomas HR, Frank MH, He YH, Xia R. TBtools: an integrative toolkit developed for interactive analyses of big biological data. Mol Plant. 2020;13(8):1194-202. https://doi.org/10.1016/j.molp.2020.06.009.

60. Lu SN, Wang JY, Chitsaz F, Derbyshire MK, Geer RC, Gonzales NR, Gwadz M, Hurwitz DI, Marchler GH, Song JS, Thanki N, Yamashita RA, Yang MZ, Zhang DC, Zheng CJ, Lanczycki CJ, Marchler-Bauer A. CDD/SPARCLE: the conserved domain database in 2020. Nucleic Acids Res. 2020;48(D1):D265-8. https:// doi.org/10.1093/nar/gkz991.

61. El-Gebali S, Mistry J, Bateman A, Eddy SR, Luciani A, Potter SC, et al. The Pfam protein families database in 2019. Nucleic Acids Res. 2019;47(D1): D427-32. https://doi.org/10.1093/nar/gky995.

62. Wilkins MR, Gasteiger E, Bairoch A, Sanchez JC, Williams KL, Appel RD, Hochstrasser DF. Protein identification and analysis tools in the ExPASy server. Methods Mol Biol. 1999;112:531-52. https://doi.org/10.1385/1-59259584-7:531.

63. Thompson JD, Gibson TJ, Plewniak F, Jeanmougin F, Higgins DG. The CLUSTAL_X windows interface: flexible strategies for multiple sequence alignment aided by quality analysis tools. Nucleic Acids Res. 1997;25(24): 4876-82. https://doi.org/10.1093/nar/25.24.4876.

64. He ZL, Zhang HK, Gao SH, Lercher MJ, Chen WH, Hu SN. Evolview v2: an online visualization and management tool for customized and annotated phylogenetic trees. Nucleic Acids Res. 2016;44(W1):W236-41. https://doi. org/10.1093/nar/gkw370
65. Hu B, Jin JP, Guo AY, Zhang H, Luo JC, Gao G. GSDS 2.0: an upgraded gene feature visualization server. Bioinformatics. 2015;31(8):1296-7. https://doi. org/10.1093/bioinformatics/btu817.

66. Lescot $M$, Déhais $P$, Thijs $G$, Marchal $K$, Moreau $Y$, Van de Peer $Y$, Rouzé $P$, Rombauts S. PlantCARE, a database of plant cis-acting regulatory elements and a portal to tools for in silico analysis of promoter sequences. Nucleic Acids Res. 2002;30(1):325-7. https://doi.org/10.1093/nar/30.1.325.

67. Gu ZL, Cavalcanti A, Chen FC, Bouman P, Li WH. Extent of gene duplication in the genomes of Drosophila, nematode, and yeast. Mol Biol Evol. 2002; 19(3):256-62. https://doi.org/10.1093/oxfordjournals.molbev.a004079.

68. Librado P, Rozas J. DnaSP v5: a software for comprehensive analysis of DNA polymorphism data. Bioinformatics. 2009;25(11):1451-2. https://doi.org/10.1 093/bioinformatics/btp187.

69. Clough SJ, Bent AF. Floral dip: a simplified method for agrobacteriummediated transformation of Arabidopsis thaliana. Plant J. 1998;16(6):735-43. https://doi.org/10.1046/j.1365-313x.1998.00343.x.

70. Si ZF, Liu H, Zhu JK, Chen JD, Wang Q, Fang L, Gao FK, Tian Y, Chen YL, Chang LJ, Liu BL, Han ZG, Zhou BL, Hu Y, Huang XZ, Zhang TZ. Mutation of SELF-PRUNING homologs in cotton promotes short-branching plant architecture. J Exp Bot. 2018;69(10):2543-53. https://doi.org/10.1093/jxb/ ery093.

71. Waadt R, Schmidt LK, Lohse M, Hashimoto K, Bock R, Kudla J. Multicolor bimolecular fluorescence complementation reveals simultaneous formation of alternative CBL/CIPK complexes in planta. Plant J. 2008;56(3):505-16. https://doi.org/10.1111/j.1365-313X.2008.03612.x.

72. Guo XQ, Britt RC Jr, Shan LB, He P. Agrobacterium-mediated virus-induced gene silencing assay in cotton. J Vis Exp. 2011;54:2938.

\section{Publisher's Note}

Springer Nature remains neutral with regard to jurisdictional claims in published maps and institutional affiliations.
Ready to submit your research? Choose BMC and benefit from:
- fast, convenient online submission
- thorough peer review by experienced researchers in your field
- rapid publication on acceptance
- support for research data, including large and complex data types
- gold Open Access which fosters wider collaboration and increased citations
- maximum visibility for your research: over $100 \mathrm{M}$ website views per year
At BMC, research is always in progress.
Learn more biomedcentral.com/submissions 